\title{
Hacia una metodología de evaluación de los sitios web de las dependencias ambientales de gobiernos de la frontera norte
}

\section{Toward a methodology for evaluating website of government environmental agencies in the northern border} Jesús Ignacio Castro Salazar* y Djamel Toudert**

\section{Resumen}

Actualmente, diversas dependencias gubernamentales en la frontera norte mexicana hacen uso de los sitios web para proporcionar información y servicios a la sociedad con el propósito de lograr una mejor interacción en torno al quehacer ambiental. Pese a eso, y a que diversos planes y programas de gobierno establecen objetivos que debe cumplir esta oferta en línea, aún se sabe poco en qué medida estos objetivos se están alcanzando. Por ello, este estudio intenta averiguar en qué medida dichos sitios cumplen los objetivos que motivaron su creación y puesta en línea. A partir de esta valoración inicial se corrobora que los sitios web estatales y municipales son proclives a un menor cumplimiento de objetivos. Se observó que el objetivo que cumplió en mayor medida en los tres niveles de gobierno fue ofertar servicios visibles y estructurados, y en menor medida instrumentar la participación ciudadana.

Palabras clave: evaluación de sitios web, gobierno electrónico, dependencias ambientales, frontera norte.

\section{Abstract}

At present, diverse government agencies in the environmental field of the northern Mexican border make use of websites to provide information and services to society in order to achieve a better interaction about the environmental work. In spite of that, and since there are various schemes and government programs that set objectives to be met by this online offer, little is known about the extent of achievement of these objectives. Therefore, this study tries to find out if these sites are fulfilling the objectives that motivate their creation and their setting online. From this initial assessment, it is confirmed that local government's websites are likely to have a lower compliance of objectives. It was observed that the objective that is more often fulfilled on the three levels of government was offering visible and structured services, in a lesser extent to implement citizen participation.

Keywords: website evaluation, e-government, environmental agencies, northern border.

Recibido el 30 de julio de 2013.

Aprobado el 27 de febrero de 2014.

* Inspector de la Procuraduría Federal de Protección al Ambiente. Correo electrónico: jicastro13@hotmail.com

** Investigador de El Colegio de la Frontera Norte. Correo electrónico: toudert@ colef.mx. 


\section{Introducción}

La incorporación de tecnologías de la información y la comunicación (TIC), particularmente internet, en la mayoría de los ámbitos de la sociedad, economía y gobierno es un hecho que parece caracterizar los grandes cambios que se han plasmado con la globalización y la mundialización del capitalismo (Camilleri y Falk, 1992; Graham, 1998; Castells, 2002). En el ámbito gubernamental, fue a mediados de la década de 1990 cuando internet comenzó a utilizarse, trayendo consigo lo que se ha identificado como una nueva etapa en la administración e interacción entre gobierno y gobernados (Criado y Ramilo, 2001; Araiza, Gutiérrez, Araiza, Sapién y Piñón, 2009; Luna-Reyes, Hernández y Gil-García, 2009; Luna-Reyes, Gil-García y Sandoval, 2010).

En ese sentido, autores como Sotelo (2006) consideran que internet, vista como un instrumento para lograr un buen gobierno, se ha vuelto la herramienta que podrá integrar al ciudadano en la gestión pública. Dicha perspectiva viene a gravitar alrededor de un conglomerado conceptual y práctico llamado "gobierno electrónico" (e-Gobierno), ${ }^{1}$ desde el cual se plantea fomentar la participación ciudadana para mejorar la gestión pública y sus corolarios: la transparencia y el acceso a la información gubernamental, la simplificación de trámites y la reducción del tiempo de espera para llevar a cabo dichos procesos (OCDE, 2003a; Banco Mundial, 2011).

En el marco de esta nueva dinámica online que parece empapar a diversos rubros del quehacer gubernamental, la gestión ambiental también se vio contagiada por las lógicas de instrumentación antes mencionadas (UNDESA, 2012). De hecho, los intentos iniciales de acercar estas herramientas a la administración ambiental encontraron sentido en los referentes ecológicos que suelen atribuirse a las TIC, aspectos que se fundieron en el pragmatismo que centra Martínez (2007) en mejorar los servicios correspondientes al sector ambiental a través del uso de internet en las dependencias de gobierno. En estas perspectivas se inscribieron varias orientaciones de organizaciones internacionales como la del Departamento de Asuntos Económicos y Sociales de las Naciones Unidas (UNDESA, por sus siglas en

${ }^{1}$ Algunos autores, como Lara, Martínez y Gómez (2004), y Criado y Ramilo (2001), consideran a e-Gobierno un concepto anglosajón, y proponen para el habla hispana el término administración electrónica. 
inglés) (2012, p. 6), que establece como techo mínimo la importancia de la presencia permanente en línea de servicios básicos ambientales para estimular la interacción entre gobierno y gobernados.

Dentro de esta agitación que enfrentó la administración pública ambiental de países desarrollados y emergentes, como se abordará más adelante, México no se quedó al margen. En efecto, según lo observado, en los tres niveles de gobierno (federal, estatal y municipal) se construye y difunde un posicionamiento favorable y muchas veces voluntarista en lo referente al uso de sitios web en dependencias ambientales gubernamentales. Globalmente, estos posicionamientos ponen especial énfasis en aclarar que lo que se busca a través de la web gubernamental es ofertar servicios integrales a los ciudadanos, incluyendo, entre otras ventajas, agilizar la realización de trámites, facilitar el acceso a la información pública, mejorar la relación entre dependencias de gobierno, favorecer la transparencia de la información y fomentar la participación ciudadana (Semarnat, 2007; SPABC, 2009). Y debido a que en un espacio nacional que padece todavía de una baja percepción ciudadana del quehacer gubernamental, estas medidas e instrumentos llegan en un momento propicio para replantear los términos de la interacción hacia esquemas participativos de gestión.

Sin embargo, más allá del alcance discursivo y las buenas intenciones que puedan caracterizar a estas visiones de integración ciudadana y de eficiencia de la gestión pública por medio de la instrumentación digital en línea, el determinismo tecnológico que parece estructurar los orígenes de estas propuestas como su carácter de "caja negra" hacen eminente la necesidad de supervisión externa y, sobre todo, la evaluación de las experiencias emprendidas. En este sentido, y pese a la inversión que los gobiernos hacen en estos instrumentos y la creciente digitalización de información y servicios ofrecidos en sitios web gubernamentales, aún se sabe poco sobre el cumplimiento de los objetivos que presidieron la incorporación de estas herramientas (Luna-Reyes, Gil-García y Sandoval, 2010). Así, tanto Beierle y Cahill (2000) como Gupta y Jana (2003) ven en la necesidad de evaluación de dichos instrumentos un paso primordial para conocer su impacto en la gestión ambiental y, desde luego, para aportar las medidas correctivas que impone el diseño institucional de cualquier objeto sistémico y/o instrumental. 
Cabe mencionar que la evaluación de estos instrumentos web gubernamentales aparece como una acción intrínseca a la incorporación misma de estas herramientas y llega a enfocarse, generalmente, a partir de un abordaje pragmático y dual: la eficiencia instrumental vista en el marco de una ecuación relativa a los propósitos de su adopción (Leff, 2002; Semarnat, 2006; Bouzas y Mahou, 2011) y el rendimiento presupuestal enfocado desde su vertiente de inversión pública (Cruz, 2003; Mosse y Whitley, 2004; Gálvez, 2010). La idea de evaluación de los sitios web, que son un reflejo real de las políticas digitales inherentes a algunos modelos de gobierno en boga, constituye todavía una perspectiva en gestación buscando una profunda conceptualización y, desde luego, su legitimación por parte del conjunto de los actores involucrados en sus diversas interacciones. Aunado a esas limitantes iniciales en la adopción de las TIC en el seno de las organizaciones volcadas a prestar servicios públicos, para Alshawi, Ali y Alalwany (2007), Luna-Reyes, Gil-García y Rojas-Bandera (2007), y Luna-Reyes, Gil-García y Sandoval (2010), es en la falta de pautas que guíen la evaluación de sitios web gubernamentales donde hay que buscar las principales razones que limitan la valoración de estos instrumentos. La idea de evaluar los sitios web forma parte de una práctica fundada en la urgencia e inmediatez operativa que justifican Marcos y Rovira (2005) en la necesidad de acercar los instrumentos a las perspectivas reales para las cuales fueron creados. Este acercamiento también encuentra sentido en una cierta tendencia del discurso gubernamental que pretende ubicar el debate de la apropiación de las TIC fuera de las relaciones sociales con los individuos, la democracia, la economía y la tecnología (Wolton, 2000; Toudert, 2007).

Más allá de las dificultades que parecen marcar tanto la reflexión como la acción en la evaluación de los sitios web ambientales gubernamentales, se destaca la idea de un objeto de investigación multidimensional y fértil para una exploración que apenas comienza a mostrar todas sus potencialidades. En este sentido, la presente contribución pretende ubicarse en el marco de un esfuerzo de sistematización encaminado a generar una proposición de evaluación complementaria, que tome en cuenta el conocimiento generado en la materia tanto a nivel nacional como internacional. Por tanto, se enfocará en relatar el contexto y los resultados de una investigación dedicada a elaborar una metodología de evaluación que fue aplicada a los sitios web de las dependencias ambientales de gobiernos de 
la frontera norte. Con esta premisa, la evaluación realizada consistió en establecer en qué medida los sitios web gubernamentales cumplieron con los objetivos contemplados en los planes y programas de gobierno que motivan su creación y puesta en línea. Bajo esta perspectiva, resulta muy importante aclarar que el contexto fronterizo y ambiental que envuelve la investigación constituye, además de un elemento necesario para la acotación, un campo temático y epistemológico de un relativo dominio por parte de los conductores de la investigación.

Dicho lo anterior, la presentación del trabajo consta de cuatro secciones: la primera se enfoca en desarrollar las dimensiones y los alcances de la reflexión conceptual que nutre la práctica de la evaluación de los sitios web gubernamentales; en la segunda sección se exhiben los aspectos metodológicos y las diferentes lógicas de sistematización y tratamiento de datos que dieron sustento a este trabajo; en la tercera sección se darán a conocer los resultados de la aplicación del modelo de evaluación propuesto para los sitios web de las dependencias ambientales de los diferentes niveles de gobierno de las entidades fronterizas.

\section{Evaluación de sitios web gubernamentales: Antecedentes, retos y alcances}

Derivado de la poscrisis petrolera de mediados de la década de 1970 que puso en aprietos al Estado ${ }^{2}$ de esos años, surgió el punto de partida para una cadena de cambios en los diferentes ámbitos económicos, políticos y sociales (Held y McGrew, 2003; Farge, 2007; Briceño y Ávila, 2010). Entre las grandes dinámicas que marcaron dicha época, las deslocalizaciones industriales, la privatización y la reestructuración de la administración pública, que llegaron a su punto culminante durante la década de 1980, definieron los rasgos de las mutaciones socioeconómicas y políticas que plasmaron el triunfo del mercado y la mundialización del capitalismo (Camilleri y Falk, 1992; Castells, 2002; Toudert, 2003).

${ }^{2}$ En los años de la década de 1970 era común el tipo de Estado de providencia, caracterizado por un gobierno representado por una administración centralizada y complicadas relaciones formales entre estados y ciudadanos, entre otras características (Heald y McGrew, 2003). 
Es en medio de este contexto agitado que se logran los acercamientos iniciales entre un ideal de administración pública eficiente y las aspiraciones a la digitalización que favorece la intensificación del desarrollo de las TIC como principal consecuencia de la privatización de los antiguos monopolios telefónicos nacionales (Graham, 1998; Castells, 2002). En el marco de esta interacción multidimensional con las variables que caracterizaron a esta época, surge la nueva gerencia pública (NGP), enfoque que se define como reformador y modernista de una perspectiva de la administración pública juzgada anticuada para enarbolar soluciones eficientes para contextos sociales cada vez más urbanos y terciarizados (Aguilar, 2008; Olías de Lima, 2001; Martínez, 2007).

Con los enfoques de esta NGP se establecieron las bases fundamentales que sellarían más adelante una fuerte alianza con las iniciativas de e-Gobierno y sus corolarios: el uso intenso de las TIC en las dependencias de gobierno y la adopción de pautas de evaluación para mejorar la eficiencia y eficacia de las acciones de los gobiernos (Gil-García, Arellano-Gault y Luna-Reyes, 2010; Briceño y Ávila, 2010; Aguilar y Bustelo, 2010). Estas iniciativas de integración intensiva de las Tic en las entrañas de la administración pública, se aceleran y se difunden prácticamente en todo el orbe a partir de la liberación de internet al consumo y el advenimiento de la web en los inicios de la década de 1990 (Castells, 2002; Toudert, 2003). La adopción del uso de internet en las dependencias de gobierno adquiere una posición central en la NGP que visualiza estos instrumentos en un marco pragmático volcado a incrementar la productividad de las acciones de gobierno y la eficiencia de su desempeño (Bonina, 2005; Bonina y Cordella, 2008; Gil-García, Arellano y Luna-Reyes, 2010; Sánchez, 2010). En este sentido, los gobiernos de distintos países, incluyendo México, comenzaron a adoptar el uso corporativo y público de internet en las diferentes dependencias (McLaughlin, Osborne y Ferlie, 2002; Rodríguez, 2004).

La relación entre la vertiente de la administración pública que vincula, principalmente, la NGP y la creciente digitalización en línea del quehacer gubernamental encuentra en el e-Gobierno el instrumento de apoyo para transformar la interacción con los ciudadanos, las empresas y otras organizaciones tanto gubernamentales como no gubernamentales (Relyea, 2002; Martinelli, 2003; OCDE, 2003a; Gil-García et al., 2010; Banco Mundial, 2011). En México, la temprana y tímida incursión del gobierno de 
Ernesto Zedillo Ponce de León (1994-2000) en internet dio paso durante el gobierno del presidente Vicente Fox Quezada (2000-2006) a un evidente propósito de involucrar estrategias de acción en línea en el marco de un proyecto nacional de e-Gobierno (Toudert, 2003; Araiza et al., 2009; Sánchez, 2009; Alberro, 2010). De hecho, el proyecto e-México del sexenio en cuestión buscaba fomentar la transparencia de la información, facilitar el acceso a los servicios públicos, llevar acabo transacciones y trámites en línea, reducir fronteras institucionales y promover la participación ciudadana (Toudert, 2003; Gil-García, Mariscal y Ramírez, 2008). Estos propósitos, como se detallará más adelante, estaban aún presentes en los planes y programas de gobierno de la administración del presidente Felipe Calderón Hinojosa (2006-2012).

En materia ambiental, con la incorporación de las dependencias ambientales en las dinámicas centrales online, el gobierno mexicano pretende que los sitios web implicados sean instrumentos que contribuyan de manera implícita o explícita a lograr los propósitos de eficiencia en los procesos de gestión ambiental que se desprenden de los planes y programas (Semarnat, 2006; 2011). En este sentido, ha sido tal la aceptación del uso de sitios web en dependencias ambientales gubernamentales mexicanas que, actualmente, distintas políticas públicas del sector ambiental promueven el uso de dichos instrumentos (OCDE, 2003b; Cerbino y Richero, 2006; Concha, 2006; Sandoval, 2008). Sin embargo, al igual que los demás instrumentos que intervienen en los procesos de gobierno, de administración y gestión pública, los sitios web gubernamentales son sujetos de evaluación y escrutinio por diferentes razones que pueden estructurar los términos de un interés público (Benjamín y Whitley, 2004; Escher, Margetts, Petricek y Cox 2006). Como comentan Alshawi, Alahmary y Alalwany (2007), evaluar los sitios web de gobierno se convierte en un componente clave para juzgar el éxito de las acciones planteadas por los gobiernos para mejorar la gestión pública.

Las inquietudes pragmáticas de conocer, explicar y valorar en qué medida se logran los objetivos propuestos por el gobierno tiene, generalmente, la finalidad de aportar información y elementos, principalmente correctivos, al proceso de toma de decisiones para el mejoramiento constante de cualquier actividad o instrumento utilizado en la gestión pública (Cardozo, 2006; Aguilar y Bustelo, 2010). En este sentido, aunque la evaluación de 
políticas de gobierno goza de una experiencia amplia que se ha consolidado con el tiempo (Whittingham y Ospina, 2000; Martínez, 2007), se hace notar la necesidad de evaluar el desempeño de las estrategias y herramientas online de las distintas dependencias de gobierno (Criado y Ramilo, 2001). Lo anterior se desprende, en gran medida, del carácter novedoso de la aplicación de estos instrumentos y al tomar en cuenta que las iniciativas para su evaluación, tanto en la teoría como en la práctica, han demostrado ser complejas y obedecen a desfases temporales (Gupta y Jana, 2003; Criado y Ramilo, 2001). Esta complejidad en la evaluación se debe, principalmente, a los múltiples factores involucrados en este tipo de proyectos, los cuales se convierten en retos por vencer (Alshawi, Alahmary y Alalwany, 2007). Como comenta Gupta y Jana (2003), a pesar de que las políticas públicas son el componente principal en la iniciativa de e-Gobiernos, los aspectos de contenido y técnicos de los sitios web gubernamentales, aunque desempeñan un papel secundario, son igual de importantes cuando se pretende evaluar ese tipo de proyectos.

Entre las propuestas teóricas para la evaluación de los sitios web de gobierno se encuentran las presentadas por Gupta y Jana (2003), Kunstelj y Vintar (2004), Alshawi, Alahmary y Alalwany (2007) que concuerdan en la importancia de evaluar el contenido y la calidad de los servicios, así como los aspectos técnicos de esos sitios. Respecto de la vertiente de la práctica de evaluación propiamente dicha, los modelos de valoración de los sitios web de gobierno se originan, principalmente, en la Unión Europea, en la Organización para la Cooperación y el Desarrollo Económicos (OCDE) y en otros países desarrollados como Estados Unidos (Fragoso, 2002). Mientras que en los países latinoamericanos aún existen pocas investigaciones y una escasa experiencia en la evaluación de la actividad online de los diferentes niveles de gobierno (Luna-Reyes, Gil-García y Rojas-Bandera, 2007). A pesar de eso, aunque aún en pequeña escala, hoy en día se aprecian cada vez más iniciativas hacia la evaluación de sitios web gubernamentales, los cuales se encuentran sumidos al escrutinio de los diferentes observadores institucionales y no institucionales sustentados en distintos modelos de evaluación en curso de elaboración y, sobre todo, de maduración (Choudrie, Ghinea y Weerakkody, 2004; PNUd, 2011).

En el marco de estos esfuerzos de conceptualización y puesta en práctica de modelos de evaluación de los sitios web gubernamentales, asistimos a 
la emergencia de diferentes lógicas estructuradas alrededor de perspectivas comparadas. A escala mundial, los modelos desarrollados por el UNDESA (2010 y 2012), West (2008) y Obi (2012) se encuentran enfocados a generar pautas que permiten tomar el pulso del estado en que se encuentran los sitios web de las dependencias gubernamentales de distintos países. En el seno de estos últimos, investigadores como Gant, Gant y Johnson (2002) en Estados Unidos; Criado y Ramilo (2001) en España; Rodríguez (2006) en Colombia; Barahona, Zuleta y Calderón (2010) en Costa Rica; y Sandoval-Almazán, Luna-Reyes y Gil-García (2011) en México, se han enfocado a diseñar y proponer metodologías y modelos nacionales para evaluar y comparar los sitios web de gobierno. En lo que respecta a la evaluación de sitios web gubernamentales del sector ambiental, las experiencias son pocas, encontrándose entre ellas el estudio realizado por Beierle y Cahill (2000), quienes evaluaron el cumplimiento de la democracia electrónica en las dependencias ambientales de gobierno de Estados Unidos, y el estudio realizado por el UNDESA (2012) que examinó el esfuerzo llevado a cabo por 193 países para suministrar información y servicios ambientales online.

A grandes rasgos, dichas investigaciones buscan evaluar en los sitios web gubernamentales diferentes características asociadas con la entrega de información y servicios al ciudadano, así como con la incorporación de herramientas enfocadas en mejorar el vínculo entre el sitio web de gobierno y los ciudadanos. Lo que lleva a definir, y en ocasiones a coincidir, distintas dimensiones generales para evaluar los sitios web de las dependencias de gobierno a fin de cumplir los objetivos que se esperan alcanzar a través de ellos. Entre estas dimensiones propuestas en las investigaciones señaladas (resumidas en el cuadro 1), unas están enfocadas en la forma de desplegar la información o los servicios en línea, mientras que otras están centradas en aspectos inherentes a la generación de los diferentes contenidos disponibles en los sitios de gobierno. El manejo cruzado de estas dos vertientes, con sus respectivas dimensiones de estructuración de un sitio web gubernamental, llega a considerarse como propósito intrínseco (objetivos) que debe cumplir la actividad online del gobierno según la experiencia de las investigaciones mencionadas. Para el caso mexicano, como mencionan Luna-Reyes, Gil-García y Sandoval (2010), muchos de esos objetivos por cumplir se encuentran en algunos marcos legales y políticas públicas que promueven el desarrollo de sitios web del gobierno. 


\begin{tabular}{|c|c|c|c|}
\hline 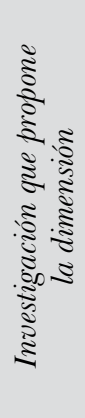 & 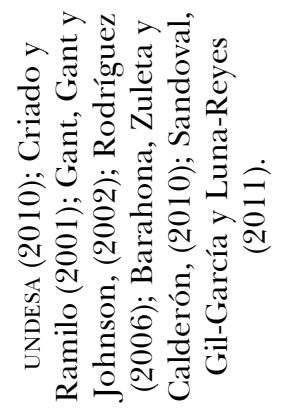 & 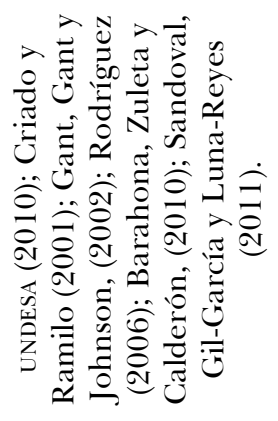 & 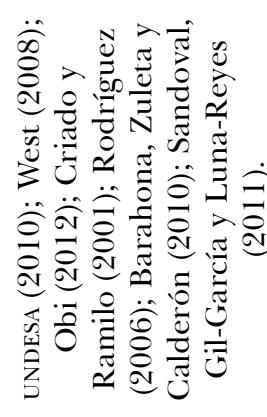 \\
\hline 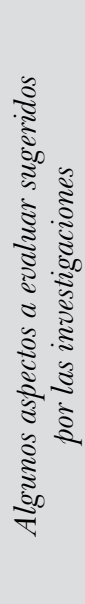 & 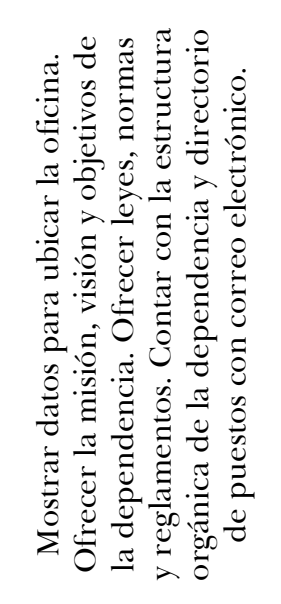 & 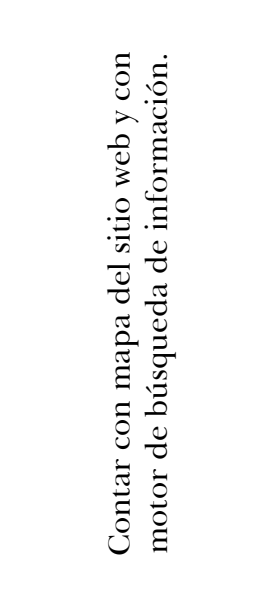 & 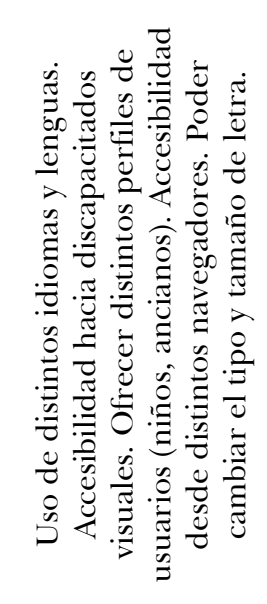 \\
\hline 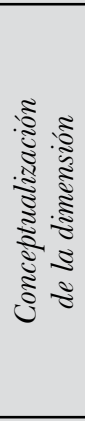 & 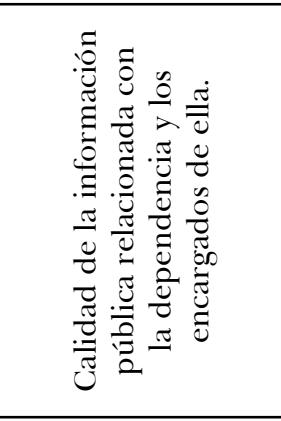 & 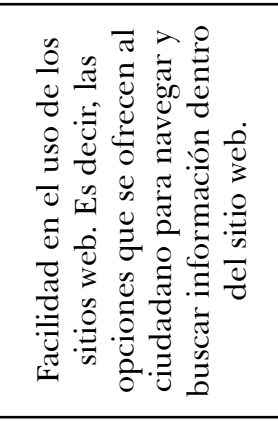 & 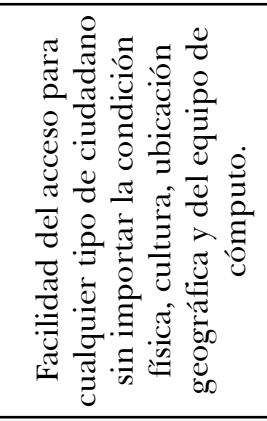 \\
\hline 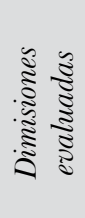 & 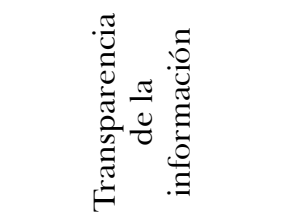 & 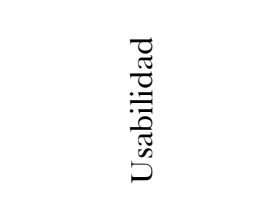 & 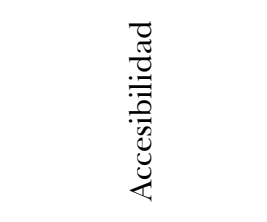 \\
\hline
\end{tabular}


Estudios Fronterizos, nueva época, vol. 15, núm. 29, enero-junio de 2014

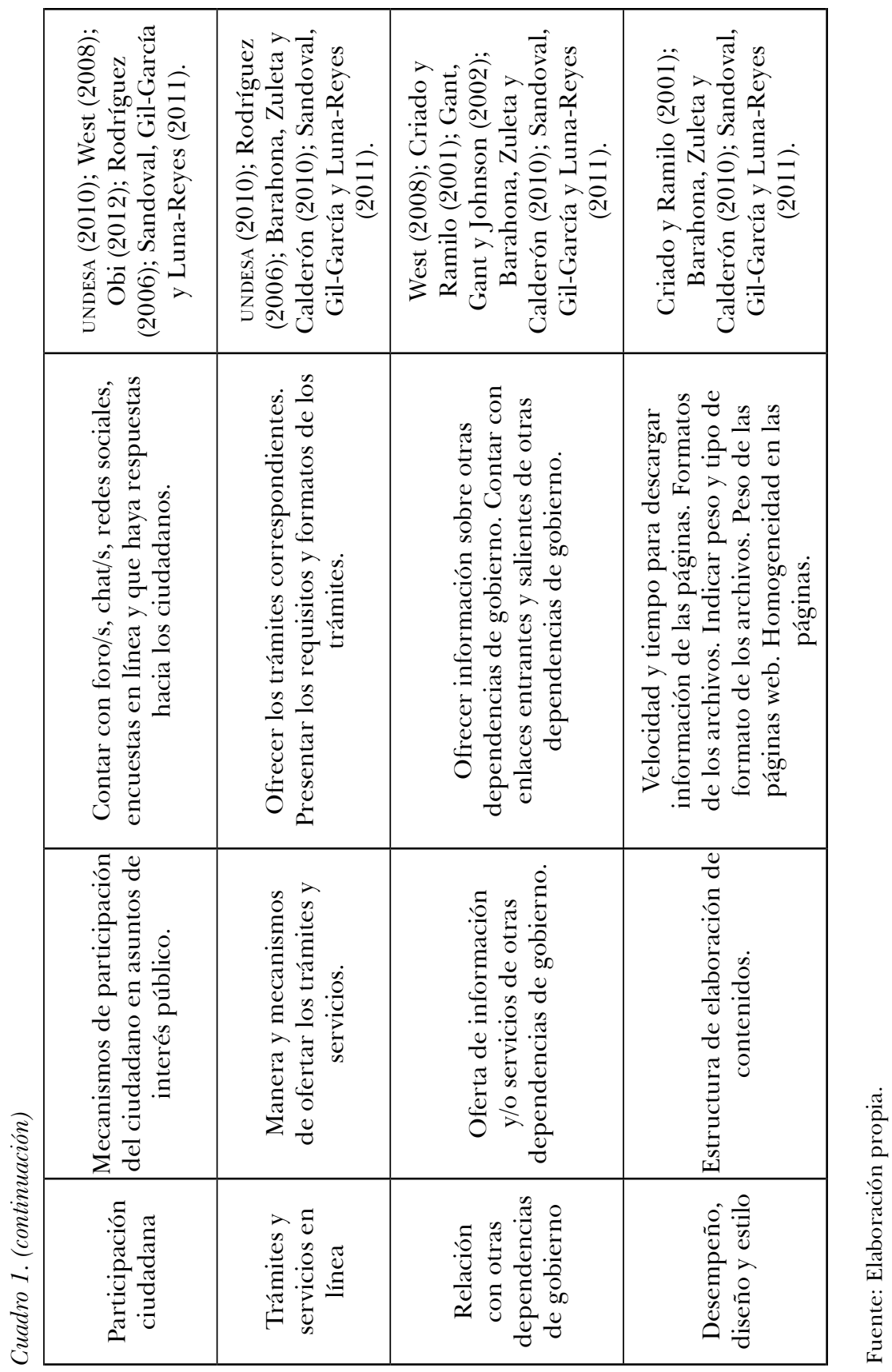


Las dimensiones presentadas pueden entenderse como los objetivos generales que deben cumplir los sitios web de gobierno, donde los aspectos evaluados en cada dimensión permitirán dar a conocer en qué medida se cumple la dimensión (objetivo). Cabe señalar que para evaluar las dimensiones existen recomendaciones, entre ellas las presentadas por Choudrie, Ghinea y Weerakkody (2004), quienes proponen que los modelos evaluativos de sitios web deben evitar el uso de criterios subjetivos a fin de disminuir juicios de valor por parte del evaluador y deben procurar utilizar más unidades donde sea posible elegir una opción correcta entre varias; además, se recomienda utilizar herramientas automáticas para evaluar ciertos aspectos técnicos. Dicha recomendación, según los autores, permitirá obtener resultados que van más allá de la opinión del evaluador, lo que favorece que al final los resultados puedan ser verificables, y permitirá evaluar con mayor precisión ciertos aspectos que de otra manera sería complicado evaluar, como la velocidad y el tiempo para descargar las páginas de los sitios web de gobierno.

\section{Evaluación de sitios web gubernamentales: Metodología}

Con la finalidad de concretar el objetivo planteado, que consiste en averiguar en qué medida los sitios web gubernamentales cumplen los propósitos contemplados en los planes y programas que motivaron su instrumentación, se procedió en dos tiempos. Al inicio fue necesario elaborar un modelo de evaluación sustentado en diferentes experiencias de aplicación, y en seguida, utilizar el modelo obtenido para valorar los sitios en línea de las dependencias ambientales de los gobiernos de la frontera norte.

Para la identificación de los sujetos de investigación que se definen por los sitios web de las dependencias ambientales de los diferentes niveles de gobierno en la frontera norte, se llevó a cabo una revisión documental que permitió identificar, en términos legales, las principales dependencias ambientales a cargo de la administración ambiental. La información revisada consistió en leyes orgánicas de la administración pública y diferentes normativas ambientales de los gobiernos federales, estatales y municipales, por 
ser los documentos que reconocen y dan atribuciones a las dependencias ambientales de gobierno. Dichas leyes ${ }^{3}$ establecen cuáles son las dependencias ambientales gubernamentales más importantes encargadas de evaluar, promover, formular, fomentar, vigilar, administrar, elaborar, otorgar y decidir sobre asuntos ambientales en sus respectivas competencias, así como establecen cuáles son las dependencias encargadas de instrumentar y coordinar las políticas, estrategias, programas y acciones relacionadas con el cuidado del medio ambiente.

Una vez determinado el universo de dependencias ambientales de los respectivos niveles de gobiernos de la frontera norte, se procedió a examinar si dichas estructuras contaban con un sitio web accesible al público. En efecto, a pesar de la importancia de entablar una presencia en línea que envuelve generalmente la vertiente tecnológica del discurso de los representantes públicos, la mayoría de las entidades gubernamentales, especialmente en el nivel municipal, no cuenta con esta presencia. Lo anterior se tradujo en la identificación y selección de una dependencia federal, seis estatales y 19 municipales, mismas que se documentan en el cuadro 2. Identificados y seleccionados los sitios web de las dependencias ambientales, se dio paso a una próxima etapa que consistió en la elaboración del modelo de evaluación (véase cuadro 2).

La confección del modelo de evaluación se realizó en el marco de tres fases sucesivas. La primera consistió en identificar los objetivos asignados

${ }^{3}$ Las leyes orgánicas de la administración pública y las leyes ambientales revisadas fueron: Ley Orgánica de la Administración Pública Federal (2009); Ley General del Equilibrio Ecológico y Protección al Ambiente (2010); Ley Orgánica de la Administración Pública del estado de Baja California (2011); Ley de protección al ambiente para el estado de Baja California (2001); Ley Orgánica del Poder Ejecutivo del estado de Sonora (2006); Ley del Equilibrio Ecológico y Protección al Ambiente del estado de Sonora (2006); Ley Orgánica del Poder Ejecutivo del estado de Chihuahua (2004); Ley del Equilibrio Ecológico y Protección al Ambiente del estado de Chihuahua (2011); Ley Orgánica de la Administración Pública del estado de Coahuila de Zaragoza (2010); Ley del Equilibrio Ecológico y la Protección al ambiente del estado de Coahuila de Zaragoza (2008); Ley Orgánica de la Administración Pública para el estado de Nuevo León (2009); Ley Ambiental del estado de Nuevo León (2011); Ley Orgánica de la Administración Pública del estado de Tamaulipas (2006); Ley de Protección Ambiental para el Desarrollo Sustentable del estado de Tamaulipas (2006). 


\section{Cuadro 2. Dependencias ambientales de gobierno a las cuales se les evaluó su sitio web}

\begin{tabular}{|c|c|c|}
\hline \multicolumn{3}{|r|}{ Federal } \\
\hline & Federal & $\begin{array}{c}\text { Secretaría de Medio Ambiente y Recursos Naturales } \\
\text { (Semarnat) }\end{array}$ \\
\hline \multicolumn{3}{|r|}{ Estatal } \\
\hline \multicolumn{2}{|c|}{ Baja California (BC) } & Secretaría de Protección al Ambiente (SPABC) \\
\hline \multicolumn{2}{|c|}{ Sonora (SON) } & Comisión de Ecología y Desarrollo Sustentable (Cedes) \\
\hline \multicolumn{2}{|c|}{ Chihuahua (CHI) } & Secretaría de Desarrollo Urbano y Ecología (Sedue) \\
\hline \multicolumn{2}{|c|}{ Coahuila (COA) } & Secretaría del Medio Ambiente (Semac) \\
\hline \multicolumn{2}{|c|}{ Nuevo León (NL) } & $\begin{array}{c}\text { Subsecretaría de Protección al Medio Ambiente y Recursos } \\
\text { Naturales (SPMARN) }\end{array}$ \\
\hline \multicolumn{2}{|c|}{ Tamaulipas (TAM) } & Secretaría de Desarrollo Urbano y Medio Ambiente (Seduma) \\
\hline \multicolumn{3}{|r|}{ Municipal } \\
\hline Estado & Municipio & Dependencia \\
\hline \multirow{3}{*}{ BC } & Ensenada & Dirección de Ecología \\
\hline & Mexicali & Dirección de Ecología \\
\hline & Tijuana & Dirección de Protección Ambiental \\
\hline \multirow{7}{*}{ SON } & Caborca & Secretaría de Desarrollo Urbano y Ecología \\
\hline & Cananea & Dirección General de Desarrollo Urbano y Ecología \\
\hline & Hermosillo & $\begin{array}{l}\text { Coordinación de Infraestructura, } \\
\text { Desarrollo Urbano y Ecología }\end{array}$ \\
\hline & Heroica Nogales & Desarrollo Urbano, Obras Públicas y Ecología \\
\hline & Huatabampo & Dependencia de Ecología y Turismo \\
\hline & Mazatlán & Dirección de Ecología y Medio Ambiente \\
\hline & Navojoa & Secretaría de Infraestructura Urbana y Ecología \\
\hline CHI & Cuauhtémoc & Desarrollo Urbano y Ecología \\
\hline $\mathrm{COA}$ & $\begin{array}{l}\text { San Juan de } \\
\text { Sabinas }\end{array}$ & $\begin{array}{c}\text { Dirección General de Ecología e Imagen } \\
\text { Urbana y Lagunas de Oxidación }\end{array}$ \\
\hline \multirow{5}{*}{ NL } & Anáhuac & Departamento de Ecología \\
\hline & Gral. Escobedo & Secretaría de Desarrollo Urbano y Ecología \\
\hline & Guadalupe & Centro de Desarrollo Urbano y Ecología \\
\hline & Monterrey & Secretaría de Desarrollo Urbano y Ecología \\
\hline & $\begin{array}{l}\text { San Pedro Garza } \\
\text { García }\end{array}$ & $\begin{array}{l}\text { Secretaría de Medio Ambiente } \\
\text { y Desarrollo Sustentable }\end{array}$ \\
\hline \multirow{2}{*}{ TAM } & Altamira & Desarrollo Urbano y Medio Ambiente \\
\hline & Ciudad Madero & Obras Públicas, Desarrollo Urbano y Ecología \\
\hline
\end{tabular}

Fuente: Elaboración propia. 
a los sitios web de las dependencias ambientales de los gobiernos de la frontera norte. Para ello, se realizó una revisión exhaustiva en los planes de desarrollo, programas para mejorar la administración pública y programas del sector ambiental. ${ }^{4}$

Dentro de los planes y programas revisados se identificaron los nueve objetivos coincidentes siguientes: transparencia de la información, participación ciudadana, relación con otras dependencias, actualización de la información y servicios, accesibilidad de los servicios a los ciudadanos, agilidad de la oferta de servicios, visibilidad y estructura de los servicios ofertados, facilidad y ahorro del tiempo en la consulta de información y servicios, e impacto del sitio web.

${ }^{4}$ Los planes y programas revisados fueron: Plan Nacional de Desarrollo 2007-2012 (2007); Programa Especial de Mejora de la Gestión en la Administración Pública Federal 2008-2012 (2008); Programa Nacional de Rendición de Cuentas, Transparencia y Combate a la Corrupción 2008-2012 (2008); Estrategia Nacional de Participación Ciudadana (2008); Programa Nacional Hídrico 2007-2012 (2008); Programa Nacional de Remediación de Sitios Contaminados (2010); Programa Ambiental México-Estados Unidos: Frontera 2012 (2003); Plan Estatal de Desarrollo Baja California (BC) 20082013 (2008); Programa Sectorial de Desarrollo Institucional y Buen Gobierno вC 2009-2013 (2009); Programa Sectorial para el Fortalecimiento Democrático y Gobernabilidad вс 2009- 2013 (2009); Plan Estatal de Desarrollo Sonora 2010-2015 (2010); Plan Estatal de Desarrollo Chihuahua 2006-2011 (2006); Plan Estatal de Desarrollo Coahuila 2010-2016 (2010); Plan Estatal de Desarrollo Nuevo León (NL) 2010-2015 (2010); Programa Especial de Mejora Regulatoria NL 2010-2015 (2010); Programa de Modernización Administrativa y Transparencia Gubernamental NL 2010-2015 (2010); Programa Sectorial de Gobernación y Participación Ciudadana NL 2010-2015 (2010); Plan Estatal de Desarrollo Tamaulipas 2010-2016 (2010); Programa de Modernización de Instrumentos de la Gestión Ambiental Tamaulipas (2010); Plan Municipal de Desarrollo Altamira 2011-2013 (2011); Plan Municipal de Desarrollo Anáhuac 20092012 (2009); Plan Municipal de Desarrollo Caborca 2009-2012 (2009); Plan Municipal de Desarrollo Chihuahua 2010-2013 (2010); Plan Municipal de Desarrollo Ciudad Juárez 2010-2013 (2010); Plan Municipal de Desarrollo Ensenada 2011-2013 (2011); Plan Municipal de Desarrollo General de Escobedo 2009-2012 (2009); Plan Municipal de Desarrollo Los Garza García 2009-2012 (2009); Plan Municipal de Desarrollo Matamoros 2011-2013 (2011); Plan Municipal de Desarrollo Monterrey 2009-2012 (2009); Plan Municipal de Desarrollo Nogales 2010-2012 (2010); Plan Municipal de Desarrollo Piedras Negras 2010-2013 (2010); Plan Municipal de Desarrollo Playas de Rosarito 2011-2013 (2011); Plan Municipal de Desarrollo Sabinas 2010-2013 (2010); Plan Municipal de Desarrollo Saltillo 2010-2013 (2010); Plan Municipal de Desarrollo Tijuana 2011-2013 (2011). 
Una vez determinado el conjunto de objetivos concurrentes entre los diferentes gobiernos de la frontera norte, se procedió a la segunda fase, que consistió en identificar los criterios y las pautas que permitieron evaluar los objetivos previamente identificados. Para concretar lo anterior, se realizó una revisión exhaustiva en guías y normas sobre sitios web de gobierno y en investigaciones académicas ${ }^{5}$ cuyo propósito haya sido evaluar sitios web gubernamentales, ya sea a escala nacional o internacional. Aunque la selección de las guías y normas fue al azar, nueve de las 10 guíasnormas gubernamentales identificadas pertenecen a países que están entre los primeros 40 con mejor e-Gobierno, de 191 que fueron evaluados (UNDESA, 2010). Mientras que las investigaciones localizadas destacan por aportar características, indicadores, herramientas y criterios para evaluar las dimensiones de los sitios web de gobierno, unos a nivel internacional y otros local. Bajo esta perspectiva, se optó generalmente por las pautas de evaluación que contaron con más consensos en su aplicación.

El modelo de evaluación generado fue estructurado en 10 secciones, una sección por cada objetivo evaluado y una última sección que fue agregada para tomar en cuenta la especificidad ambiental de los sitios web valorados. En el marco de esta organización, cada sección estaba estructurada por las características específicas de la revisión documental realizada y, a su vez, las características fueron definidas por sus propios indicadores de valoración. En términos generales, se identificaron 77 características y 99 indicadores; a modo de ejemplo, el cuadro 3 ejemplifica, con algunas características e indicadores, la estructura del modelo de evaluación. Además, y siguiendo las recomendaciones presentadas por Choudrie et al. (2004), el cuadro 3 presenta la manera en que fueron evaluados los objetivos, procurando utilizar unidades donde era posible elegir una opción correcta entre varias a fin de evitar el uso de criterios subjetivos y

${ }^{5}$ En lo que respecta a las guías-normas de gobierno, se revisó la guía del gobierno de México (2007) y de los gobiernos de Australia (2011), Canadá (2007), Chile (2003, 2006), Costa Rica (2007), España (2004, 2007, 2009), Francia (1999), India (2009), Inglaterra (2002a, 2002b, 2009a, 2009b, 2009c, 2010a, 2010b, 2010c, 2010d, 2011) y Uruguay (2009). Respecto de las investigaciones consultadas, se revisaron las realizadas por el Departamento de Asuntos Económicos y Sociales de las Naciones Unidas (UNDESA) (2010), West (2008), Obi (2012) y Criado y Ramilo (2001) en España; Gant, Gant y Johnson (2002) en Estados Unidos; Rodríguez (2006) en Colombia; Barahona y Calderón (2010) en Costa Rica; y Sandoval-Almazán, Gil-García y Luna-Reyes (2011) en México. 
Estudios Fronterizos, nueva época, vol. 15, núm. 29, enero-junio de 2014

\begin{tabular}{|c|c|c|c|c|c|c|c|}
\hline 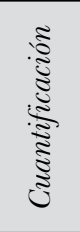 & $\begin{array}{c}0 \\
\| \\
0 \\
Z \\
\ddot{Z} \\
\ddot{11} \\
\ddot{i n}\end{array}$ & $\begin{array}{c}0 \\
11 \\
0 \\
z \\
\ddot{Z} \\
\| \\
\dot{n}\end{array}$ & $\begin{array}{l}0 \\
11 \\
0 \\
z \\
\ddot{z} \\
\| \\
i n\end{array}$ & $\begin{array}{c}0 \\
11 \\
0 \\
Z \\
\ddot{Z} \\
\ddot{11} \\
\ddot{i n}\end{array}$ & $\begin{array}{c}0 \\
11 \\
0 \\
z \\
\ddot{Z} \\
\ddot{11}\end{array}$ & $\begin{array}{l}0 \\
11 \\
0 \\
z \\
\ddot{-} \\
11 \\
i n\end{array}$ & $\begin{array}{c}0 \\
11 \\
0 \\
z \\
\ddot{-} \\
11 \\
i=\end{array}$ \\
\hline 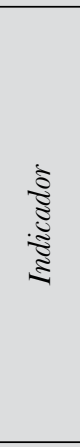 & 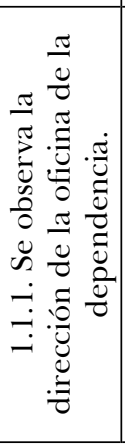 & 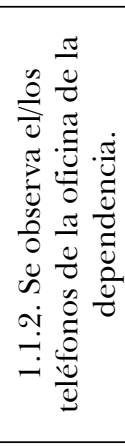 & 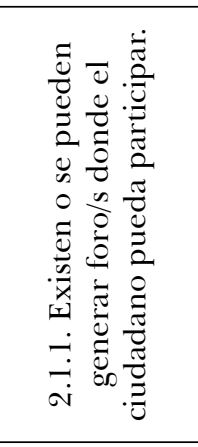 & 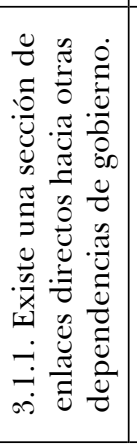 & 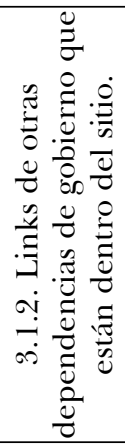 & 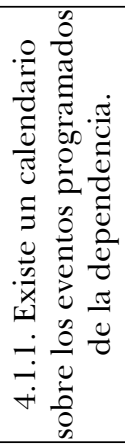 & 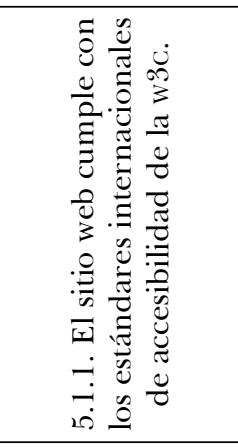 \\
\hline 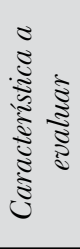 & 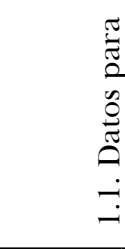 & 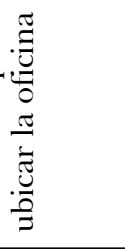 & $\begin{array}{c}n \\
0 \\
0 \\
0 \\
\dot{0} \\
\dot{\sigma} \\
\dot{v}\end{array}$ & 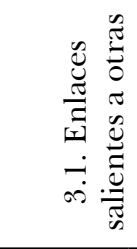 & 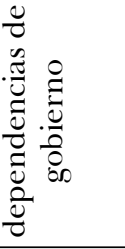 & 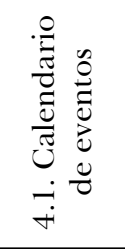 & 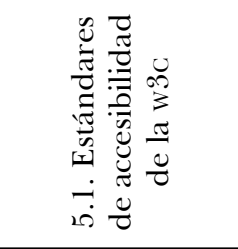 \\
\hline 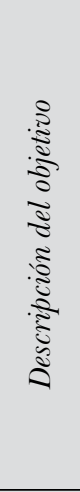 & 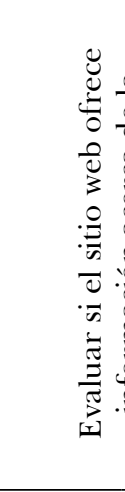 & 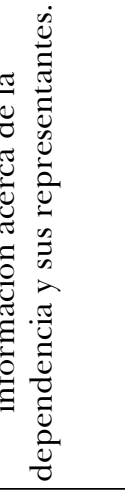 & 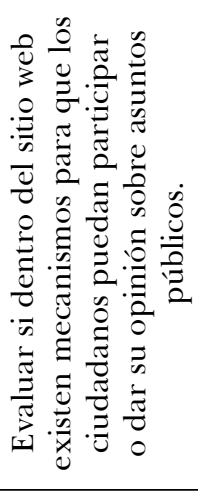 & 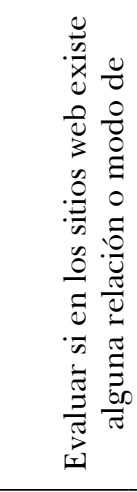 & 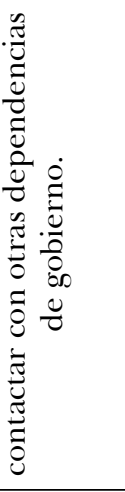 & 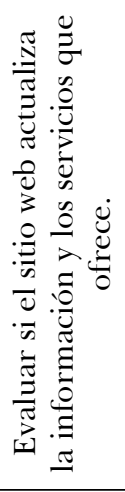 & 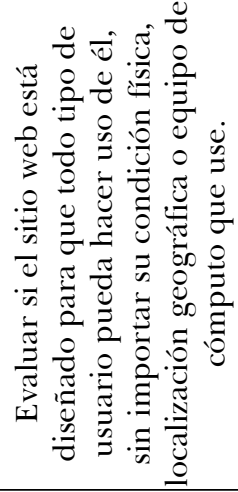 \\
\hline 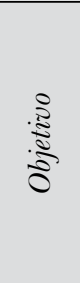 & 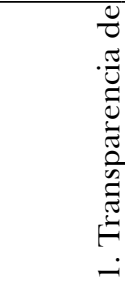 & : & 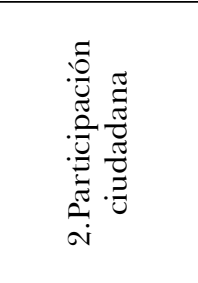 & 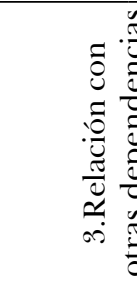 & $\begin{array}{l}0 \\
0 \\
0 \\
0 \\
0 \\
0 \\
0 \\
0 \\
0\end{array}$ & 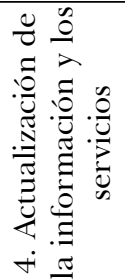 & 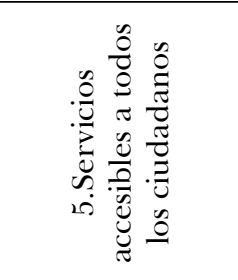 \\
\hline
\end{tabular}




\begin{tabular}{|c|c|c|c|c|c|}
\hline $\begin{array}{c}0 \\
11 \\
0 \\
z \\
\ddot{z} \\
\ddot{i n}\end{array}$ & $\begin{array}{c}0 \\
11 \\
0 \\
Z \\
\ddot{Z} \\
\ddot{11} \\
\dot{\text { n }}\end{array}$ & $\begin{array}{c}0 \\
11 \\
0 \\
z \\
\ddot{-} \\
11 \\
i=\end{array}$ & $\begin{array}{l}0 \\
11 \\
0 \\
z \\
\ddot{Z} \\
11 \\
i=\end{array}$ & $\begin{array}{l}0 \\
11 \\
0 \\
Z \\
\ddot{Z} \\
11 \\
i n\end{array}$ & $\begin{array}{l}0 \\
11 \\
0 \\
z \\
\ddot{Z} \\
11 \\
i n\end{array}$ \\
\hline 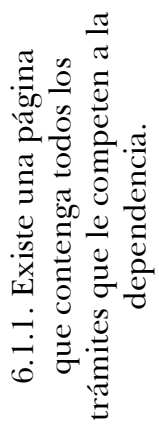 & 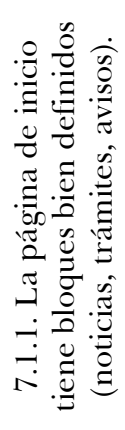 & 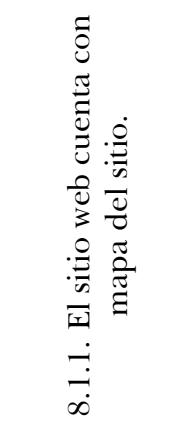 & 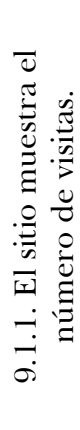 & 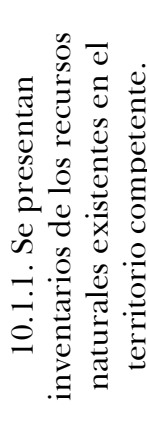 & 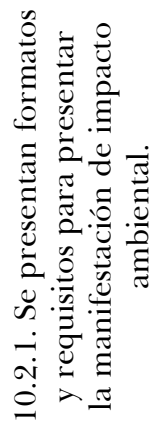 \\
\hline 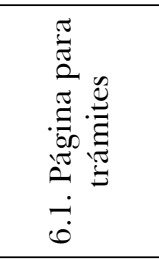 & 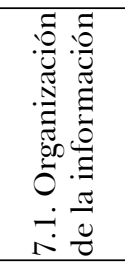 & 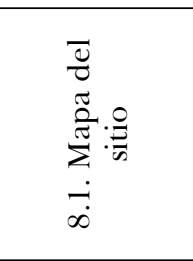 & 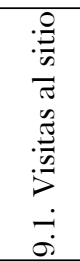 & 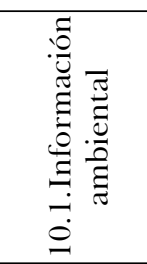 & 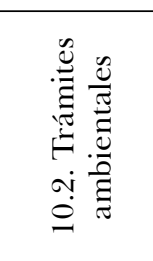 \\
\hline 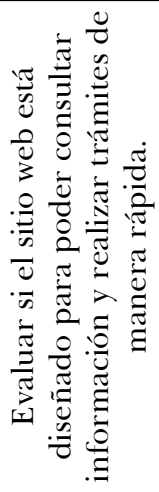 & 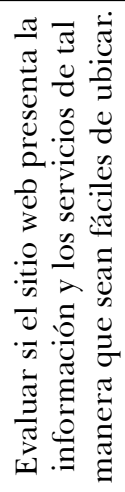 & 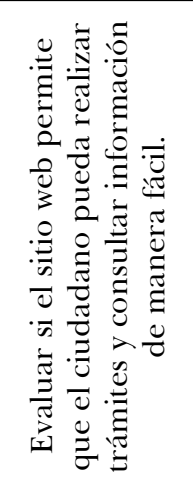 & 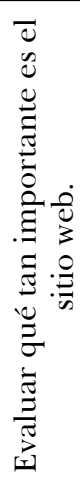 & \multicolumn{2}{|c|}{ 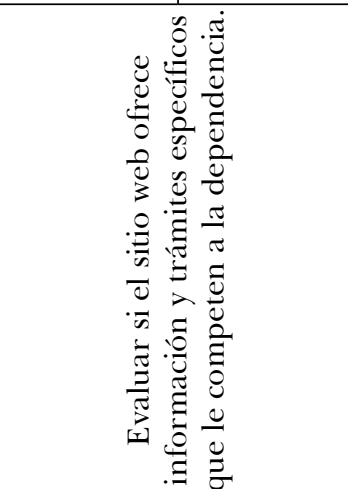 } \\
\hline 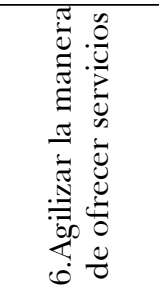 & 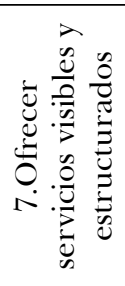 & 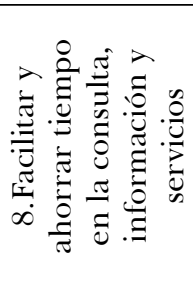 & 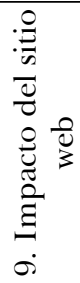 & \multicolumn{2}{|c|}{ 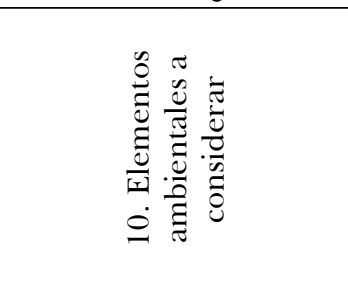 } \\
\hline
\end{tabular}


así permitir resultados que pudieran ser verificables; así, para cuantificar cada indicador se utilizó una lógica dicotómica; es decir, se le asignó al indicador evaluado " 1 " si cumplía con el indicador, y " 0 " si no cumplía con tal indicador. De esa manera, se procedió a la tercera fase: la valoración del cumplimiento de objetivos por parte de los sitios web de los gobiernos de la frontera norte.

La aplicación del modelo de evaluación obtenido se llevó a cabo tomando en cuenta algunas de las consideraciones recomendadas por SandovalAlmazán, Gil-García y Luna-Reyes (2011) con la finalidad de asegurar una valoración en condiciones semejantes a la totalidad de los sitios web evaluados. En este sentido, se fijó un periodo máximo de 60 minutos para cada evaluación de los sitios web utilizando una conexión a internet de banda ancha y apegándose firmemente a las características, indicadores y cuantificación del modelo de evaluación. Cabe señalar que continuando con los autores antes mencionados, la evaluación no trató de encontrar a como diera lugar el indicador dentro del sitio web, sólo se evaluó que el indicador estuviera a la vista para ser localizado de manera fácil y rápida.

La evaluación propiamente dicha procedió con una visita rápida (entre cinco a ocho segundos) a los sitios web con el fin de familiarizarse con la estructura del sitio; posteriormente se procedió a buscar y valorar cada uno de los indicadores presentes en el modelo de evaluación hasta revisar cada característica evaluada. Para asignar un valor a los indicadores evaluados, como se comentó, se optó por una lógica dicotómica de 0,1 para caracterizar el cumplimiento y no cumplimiento de las características. Es decir, se le asignó al indicador evaluado " 1 " si cumplía el indicador y "0" si no lo cumplía.

Una vez valorados y cuantificados todos los indicadores programados, se prosiguió a estimar en qué medida se cumplió cada uno de los 10 objetivos de la evaluación. Para ello, primero se calculó el valor de cumplimiento de cada característica y posteriormente, se calculó el valor que representaba en qué medida se cumplió cada objetivo. Para valorar el cumplimiento de cada característica, se sumaron todos los valores obtenidos de los indicadores que conformaban a la característica y se dividió esa suma entre el número de indicadores que conformaban la característica. Después, para calcular el valor que representaba en qué medida se cumplió cada objetivo, primero, se multiplicó el valor de cumplimiento de cada característica por el porcentaje, con base uno, de importancia que representaba cada característica (el 
valor de importancia de la característica fue obtenido al sumar el número de veces que aparecía cada característica en las guías-normas de gobierno y en las investigaciones revisadas y dividiéndolo entre el total de guías-normas y de investigaciones), y posteriormente se sumaron todas los resultados de las características correspondientes a cada objetivo.

En el marco de esta compleja dinámica metodológico-conceptual, se generaron los datos de la evaluación aplicada a los sitios web de las dependencias ambientales de los gobiernos de la frontera norte. Para facilitar la lectura de la importante información generada, se procedió a su presentación y discusión a partir de una lógica que procede de lo general a lo particular. Lo anterior permite resaltar las particularidades en medio de los comportamientos de conjunto posibilitando también la apreciación de ciertas lógicas que parecen sustentar la presencia en línea de las dependencias ambientales.

\section{Diferentes lógicas de presencia online: Resultados, convergencias y divergencias}

La presentación de los resultados de la investigación consta, inicialmente, de un análisis comparativo entre los diferentes niveles de gobierno de la frontera norte con la finalidad de elucidar los términos generales que parecen estructurar los niveles de cumplimiento con los objetivos de la creación de los sitios web evaluados. Posteriormente, se profundizará la perspectiva analítica de los resultados de la evaluación en el seno de los sitios web de los gobiernos estatales y municipales con el propósito de averiguar las diferencias y los matices que dan sustento a la presencia ambiental online de unos y otros. En el marco de esta dinámica analítica, independientemente de si los sitios web de las dependencias ambientales de los gobiernos de la frontera norte cumplen o no con los objetivos que justifican su existencia, es importante subrayar que el cumplimiento de objetivos en su nivel más alto se mezcla también con tasas de incumplimiento que pueden considerarse como debilidades importantes para la eficiencia de cualquier iniciativa gubernamental online.

El examen de los resultados generales deja entrever una diferencia sustancial en el cumplimiento de los objetivos contemplados por los diferentes 
niveles de gobierno en la frontera norte. En efecto, las dependencias federales registraron un cumplimiento de objetivos con una tasa de $63.6 \%$, casi dos veces más alta que las dependencias estatales $(34.8 \%)$ y aún más comparado con las municipales (28.2\%). En lo que respecta al cumplimiento de los grandes rubros evaluados, se observó que nuevamente el sitio web de la dependencia federal fue el más efectivo con $80 \%$ en lo que toca a la información ambiental, $66.7 \%$ en los trámites ambientales y $63.6 \%$ en la evaluación del conjunto de los primeros nueve objetivos enumerados en el cuadro 3. De cara a los resultados anteriores, tanto las dependencias estatales como municipales parecen al borde del cumplimiento, siendo el caso de las dependencias municipales el más obvio al no cumplir en el rubro de la información ambiental y el cumplimiento de manera muy marginal de los trámites ambientales (véase figura 1).

De manera particular, el propósito que consiste en "ofrecer servicios visibles y estructurados" fue el objetivo que se cumplió $100 \%$ en los gobiernos federales y estatales, y $95.1 \%$ en los municipales. En lo que toca al objetivo que menos se cumplió, el sitio web federal cumplió en menor medida en la "participación ciudadana" con 18.5\%, mientras que en los sitios estatales y municipales, el propósito que más se incumplió es el "impacto

Figura 1. Cumplimiento de objetivos por nivel de gobierno

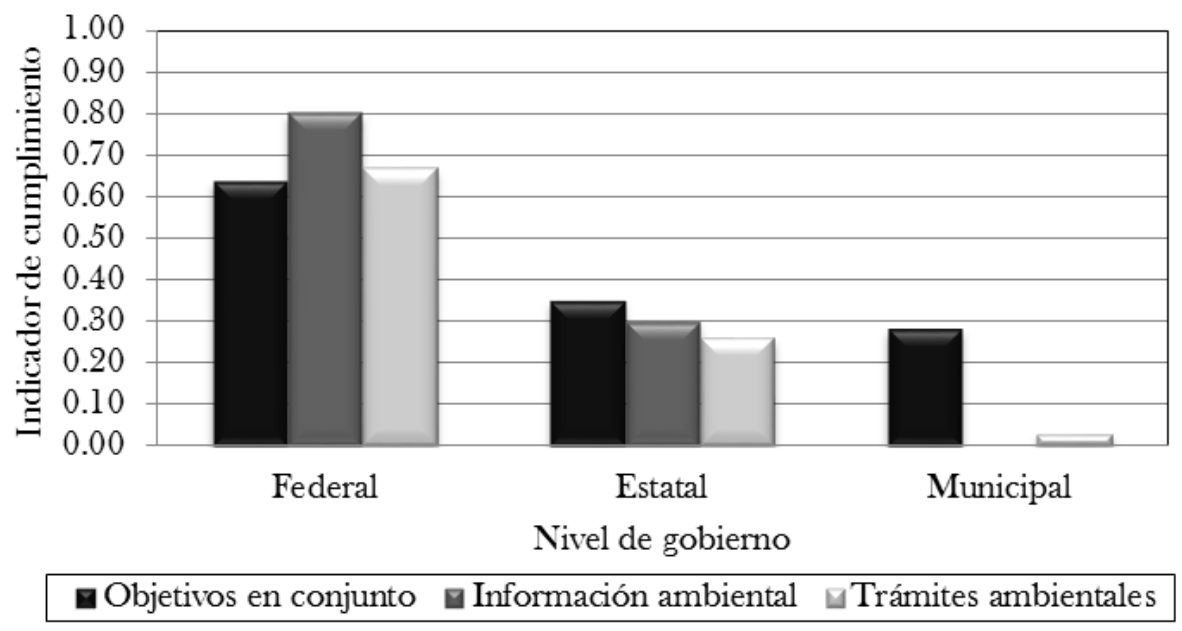

Fuente: Elaboración propia con datos obtenidos de evaluar los sitios web. 
del sitio web" con $3.0 \%$ y $5.7 \%$ de cumplimiento, respectivamente. Tomando en cuenta lo anterior, se desprende una coincidencia entre los sitios web estatales y municipales, tanto en los objetivos con el máximo cumplimiento como en los de menos cumplimiento (véase figura 2).

Con la finalidad de facilitar el entendimiento de la dinámica del cumplimiento de los sitios web de las dependencias ambientales de los gobiernos de la frontera, se estableció que en una tasa menor a $35 \%$ el sitio web no cumple el objetivo evaluado; entre $35 \%$ y $70 \%$ se cumple parcialmente; y si la tasa observada es mayor a $70 \%$, se cumple el objetivo. A partir de la segmentación anterior, se construyen las valoraciones que se presentan en el cuadro 4, en donde se aprecia que de los nueve objetivos evaluados, el sitio del gobierno federal cumplió totalmente cuatro, parcialmente otros cuatro y no cumplió en uno. A nivel estatal, los seis sitios web analizados cumplieron totalmente en uno de los nueve objetivos, cumplieron parcialmente en cuatro y no cumplieron en otros cuatro. Por último, a nivel municipal los 19 sitios web analizados cumplieron totalmente uno de los nueve objetivos, parcialmente uno y no cumplieron en siete.

\section{Figura 2. Dinámica de cumplimiento de los objetivos contemplados en la evaluación}

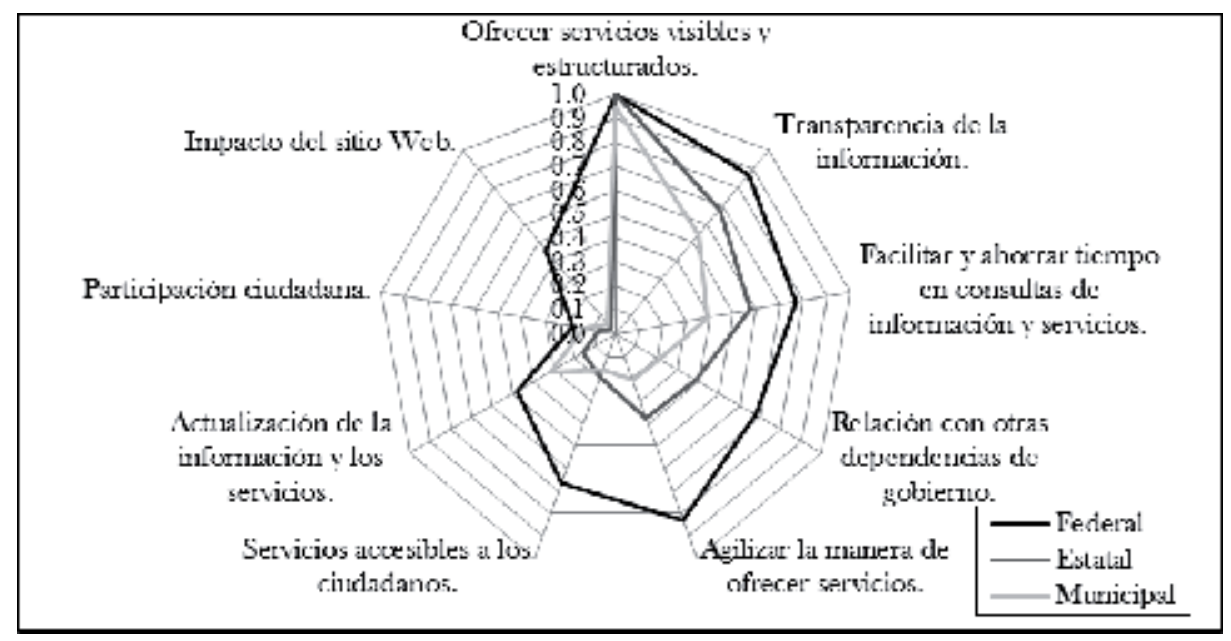

Fuente: Elaboración propia con datos obtenidos de la evaluación de sitios web. 
Cuadro 4. Cumplimiento de los objetivos por nivel de gobierno

\begin{tabular}{|l|c|c|c|}
\hline \multicolumn{1}{|c|}{ Objetivo evaluado } & Federal & Estatal & Municipal \\
\hline Ofrecer servicios visibles y estructurados. & Cumplió & Cumplió & Cumplió \\
\hline Transparencia de la información. & Cumplió & Parcialmente & Parcialmente \\
\hline Agilizar la manera de ofrecer servicios. & Cumplió & Parcialmente & No cumplió \\
\hline $\begin{array}{l}\text { Facilitar y ahorrar tiempo en consultas } \\
\text { de información y servicios. }\end{array}$ & Cumplió & Parcialmente & No cumplió \\
\hline $\begin{array}{l}\text { Actualización de la información y los } \\
\text { servicios. }\end{array}$ & Parcialmente & No cumplió & No cumplió \\
\hline $\begin{array}{l}\text { Relación con otras dependencias } \\
\text { de gobierno. }\end{array}$ & Parcialmente & Parcialmente & No cumplió \\
\hline $\begin{array}{l}\text { Servicios accesibles a todos los } \\
\text { ciudadanos. }\end{array}$ & Parcialmente & No cumplió & No cumplió \\
\hline Impacto del sitio web. & Parcialmente & No cumplió & No cumplió \\
\hline Participación ciudadana. & No cumplió & No cumplió & No cumplió \\
\hline Información ambiental. & Cumplió & No cumplió & No cumplió \\
\hline Trámites ambientales. & Parcialmente & No cumplió & No cumplió \\
\hline
\end{tabular}

Fuente: Elaboración propia con datos obtenidos de la evaluación de los sitios web.

Si bien existen divergencias entre los grados de cumplimiento a nivel federal y su equivalente a nivel estatal y municipal, también se observaron coincidencias al cumplir el objetivo de "ofrecer servicios visibles y estructurados" y al no cumplir el objetivo de fomentar la "participación ciudadana”. En cuanto al cumplimiento con los aspectos ambientales, sólo el sitio web federal cumplió el rubro de "información ambiental" y cumplió parcialmente las características analizadas en el objetivo de "trámites ambientales", mientras que los sitios web estatales y municipales no cumplieron en ambos aspectos analizados (véase cuadro 4).

Analizando los resultados de evaluación desde la perspectiva de los gobiernos estatales que reporta la figura 3, se observa que el sitio web de la Secretaría del Medio Ambiente de Coahuila (Semac) fue el que cumplió 
Figura 3. Cumplimiento de objetivos en los sitios web de los gobiernos estatales

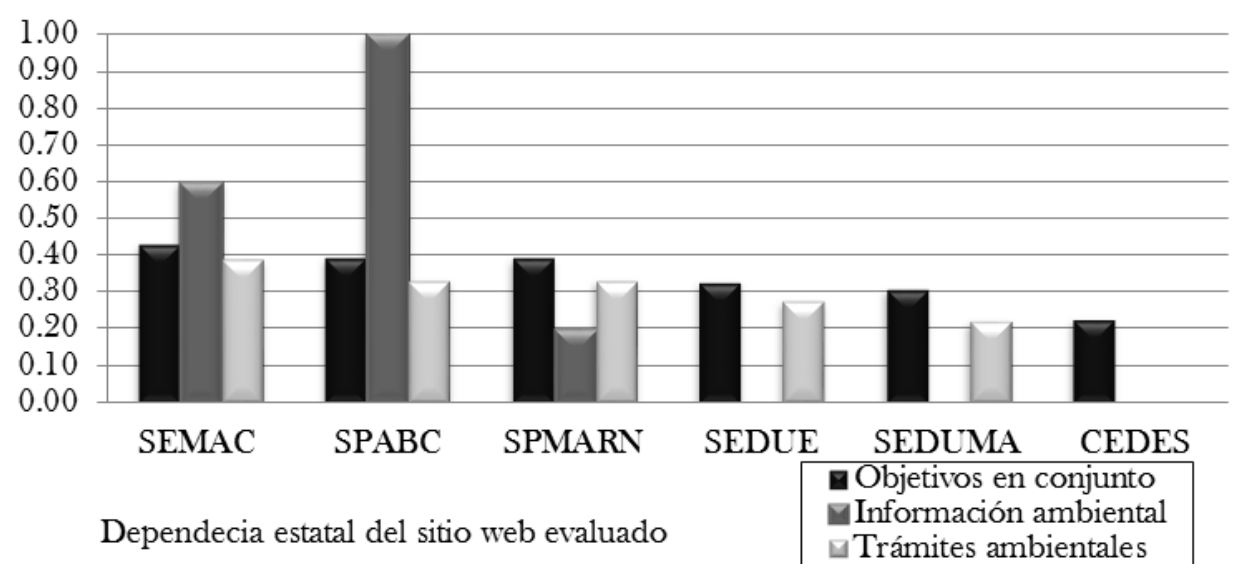

Fuente: Elaboración propia con datos obtenidos de la evaluación de los sitios web.

en mayor medida los objetivos en conjunto, con $43.4 \%$ de tasa de cumplimiento; mientras que el sitio web de la Comisión de Ecología y Desarrollo Sustentable de Sonora (Cedes) fue el que cumplió en menor medida los objetivos en conjunto, con $22.7 \%$. Independientemente de la fluctuación de las tasas óptimas de cumplimiento de los sitios evaluados, es muy importante subrayar que en su nivel más alto, el cumplimiento con los criterios valorados se ubica por debajo de la mitad del potencial de cumplimiento.

En cuanto a los aspectos ambientales evaluados, los niveles más altos de cumplimento de objetivos fueron los del sitio web de la Secretaría de Protección al Ambiente de Baja California (SPABC) que cumplió al 100\% el rubro de "información ambiental" y el sitio de la Semac que cumplió al $38.9 \%$ el rubro de los "trámites ambientales". Por su parte, el nivel más bajo de cumplimiento de objetivos lo obtuvo el sitio web de la Cedes que no cumplió ninguno de los rubros ambientales evaluados. De todo lo anterior, se desprende que el sitio web de la Cedes fue el que cumplió en menor medida los objetivos y rubros ambientales evaluados.

En el cuadro 5 se aprecia que los sitios web de la SPABC, Semac y SPMARN fueron los que cumplieron en mayor medida los objetivos evaluados, los 
Estudios Fronterizos, nueva época, vol. 15, núm. 29, enero-junio de 2014

\begin{tabular}{|c|c|c|c|c|c|c|c|c|c|c|c|c|}
\hline & & 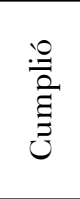 & 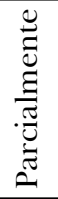 & 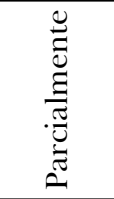 & 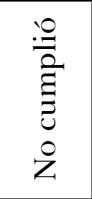 & 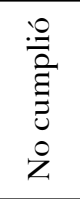 & 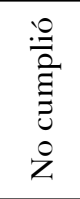 & 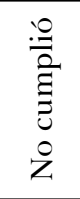 & 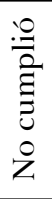 & 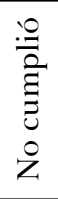 & 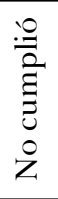 & 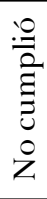 \\
\hline$\underset{\frac{1}{n}}{\frac{5}{n}}$ & & 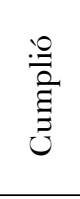 & 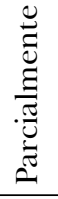 & & 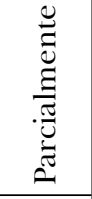 & 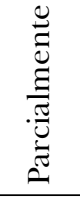 & 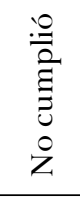 & 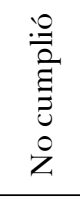 & 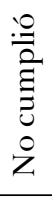 & 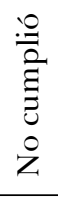 & 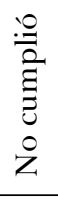 & 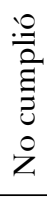 \\
\hline 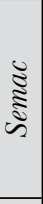 & 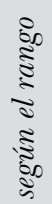 & 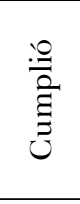 & 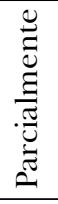 & 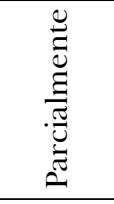 & 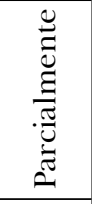 & 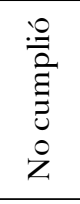 & 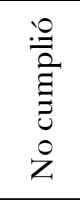 & 递 & 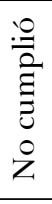 & 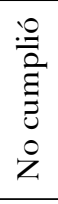 & 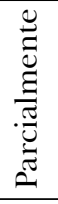 & 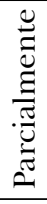 \\
\hline 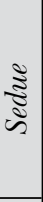 & 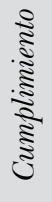 & 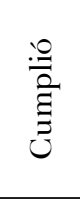 & 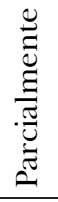 & 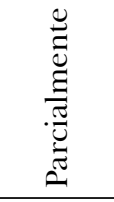 & 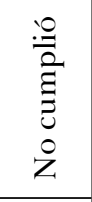 & 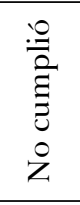 & 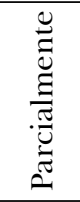 & $\begin{array}{l}: \stackrel{0}{0} \\
\stackrel{0}{\Xi} \\
\Xi \\
0 \\
0 \\
Z\end{array}$ & 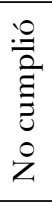 & 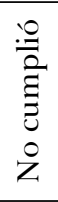 & 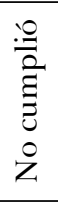 & 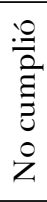 \\
\hline$\stackrel{\Xi}{\mathbb{s}}$ & & 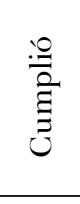 & 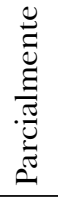 & 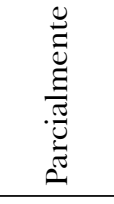 & 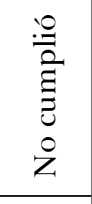 & 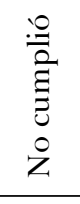 & 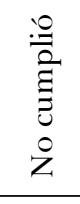 & 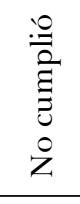 & 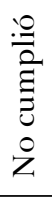 & 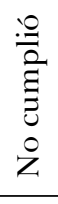 & 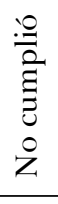 & 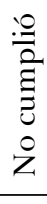 \\
\hline$\frac{\infty}{\infty}$ & & 迅 & 象 & 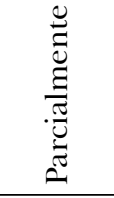 & 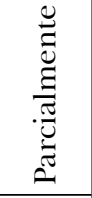 & 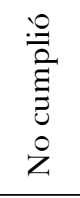 & 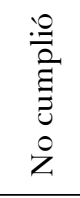 & 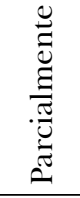 & 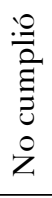 & 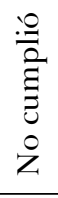 & & 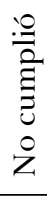 \\
\hline & & 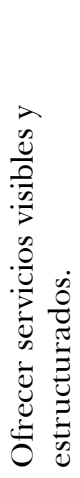 & 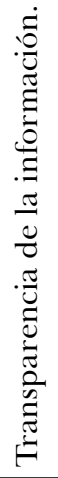 & 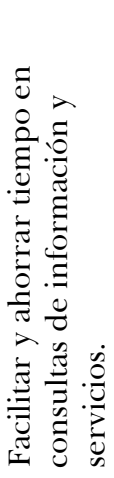 & 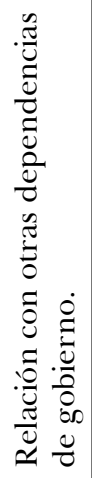 & 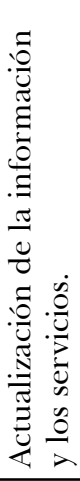 & 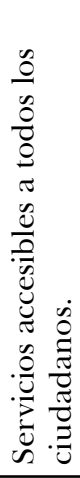 & 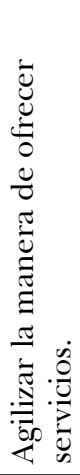 & $\begin{array}{l}\dot{0} \\
0 \\
0 \\
0 \\
0 \\
0 \\
0 \\
0 \\
0 \\
0 \\
0 \\
0 \\
0 \\
0\end{array}$ & 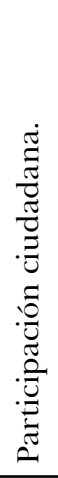 & 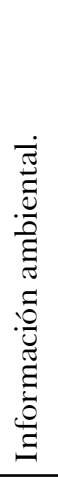 & 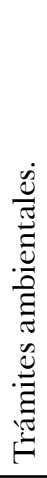 \\
\hline
\end{tabular}


tres sitios web cumplieron por lo menos dos objetivos. Se observa también que los sitios web de la Cedes y la Seduma fueron los que cumplieron en menor medida los objetivos, pues no cumplieron en seis de nueve objetivos. En cuanto a los aspectos ambientales evaluados, sólo el sitio web de la SPABC cumplió con el rubro de "información ambiental" en 100\%, el sitio web de la Semac cumplió parcialmente con la "información ambiental” y los "trámites ambientales" con $60 \%$ y $38.9 \%$ respectivamente; fuera de eso, los demás sitios web no cumplieron ninguno de los elementos ambientales evaluados.

Lo observado en el comparativo entre los sitios web ambientales deja entrever que no existe un comportamiento típico que pueda definir en su totalidad la oferta de los sitios web estatales. Mientras tanto, el análisis de los resultados de evaluación desde la perspectiva de los gobiernos municipales que reporta la figura 4 deja entrever que el sitio web de la Secretaría de Desarrollo Urbano y Ecología de Monterrey (Nuevo León) (16) fue el que cumplió en mayor medida los objetivos en conjunto con $42.1 \%$ de tasa de cumplimiento; mientras que el sitio web del Departamento de Ecología de Anáhuac (Nuevo León) (13) fue el que cumplió en menor medida los objetivos en conjunto con $16.1 \%$. De igual manera que a escala estatal, es importante señalar que la tasa de cumplimiento más alta a escala municipal también se ubica por debajo de la mitad del potencial de cumplimiento de objetivos.

En lo que respecta a los aspectos ambientales evaluados, ninguno de los 19 sitios web municipales cumplió el rubro "información ambiental"; mientras en el rubro de "trámites ambientales", el sitio web de la Dirección de Protección Ambiental de Tijuana (Baja California) (3) fue el que cumplió en mayor medida con 22.2\%, seguido del sitio web de la Dirección de Ecología de Ensenada (Baja California) (1) con $16.7 \%$ y después otros sitios con menor tasa de cumplimiento. Fuera de los cinco sitios web con tasas de cumplimiento $(6,10,9,3$ y 1), los demás sitios web municipales presentaron un nulo cumplimiento en el rubro de "trámites ambientales".

De manera general, los sitios web municipales mostraron un cumplimiento preferencial en la pauta de "ofrecer servicios visibles y estructurados", y tienden a no cumplir con las pautas de "impacto del sitio web", "participación ciudadana" y "servicios accesibles a todos los ciudadanos". En este sentido, los sitios web municipales parecen centrados 
Figura 4. Cumplimiento de objetivos en los sitios web de los gobiernos municipales

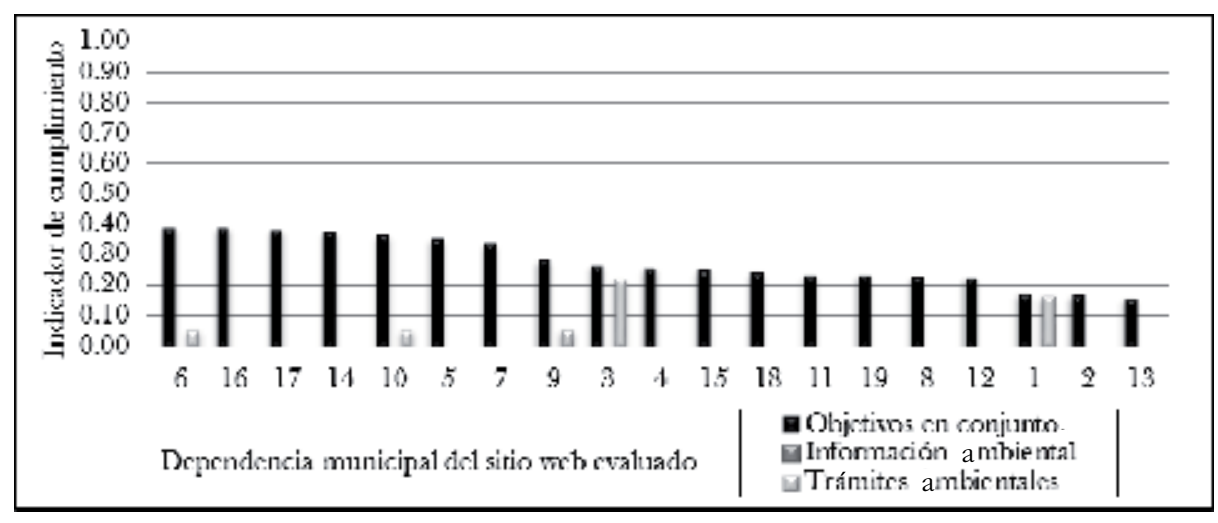

Fuente: Elaboración propia con datos obtenidos de la evaluación. Donde: 1 = Dirección de Ecología de Ensenada; 2 = Dirección de Ecología de Mexicali; 3 = Dirección de Protección Ambiental de Tijuana; 4 = Secretaría de Desarrollo Urbano y Ecología de Caborca; 5 = Dirección General Desarrollo Urbano y Ecología de Cananea; 6 = Coordinación de Infraestructura, Desarrollo Urbano y Ecología de Hermosillo; 7 = Desarrollo Urbano, Obras Públicas y Ecología de Heroica Nogales; $8=$ Dependencia de Ecología y Turismo de Huatabampo; 9 = Dirección de Ecología y Medio Ambiente de Mazatlán; 10 = Secretaría de Infraestructura Urbana y Ecología de Navojoa; 11 = Desarrollo Urbano y Ecología de Cuauhtémoc; 12 = Dirección General de Ecología e Imagen Urbana y Lagunas de Oxidación de San Juan de Sabinas; 13 = Departamento de Ecología de Anáhuac; 14 = Secretaría de Desarrollo Urbano y Ecología de Gral. Escobedo; 15 = Centro de Desarrollo Urbano y Ecología de Guadalupe; 16 = Secretaría de Desarrollo Urbano y Ecología de Monterrey; 17 = Secretaría de Medio Ambiente y Desarrollo Sustentable de San Pedro Garza García; 18 = Desarrollo Urbano y Medio Ambiente de Altamira; y 19 = Obras Públicas, Desarrollo Urbano y Ecología de Ciudad Madero.

principalmente en la comunicación, sin prestarle atención a los rubros de interacción, usabilidad y utilidad de los contenidos puestos en línea. De esta manera, nos encontramos de cara a una significativa disminución del cumplimiento con las pautas evaluadas conforme nos dirigimos hacia los gobiernos locales, cuando, paradójicamente, éstos representan los eslabones más importantes para la vida diaria de los ciudadanos.

Sin embargo, esta situación observada en los sitios web de las dependencias ambientales de los gobiernos de la frontera norte no es específica del caso mexicano, de hecho, Beierle y Cahill (2000) reportaron que los sitios web de las agencias ambientales estatales norteamericanas carecen 
de una activa interacción online entre ciudadanos y gobierno en materia ambiental. Lo anterior parece ocurrir a pesar de la fuerte penetración social de las TIC y los enormes avances que registra la normatividad estadunidense en el ámbito de la regulación de contenidos web de gobierno. A la misma reflexión parece llegar la UNDESA (2012), esto al constatar que los sitios de las dependencias ambientales de gobierno no fueron estructurados para notificar proactivamente los problemas ambientales y no proporcionan información a los ciudadanos para hacerlos partícipes en la gestión ambiental.

Bajo esta perspectiva de lo observado en un contexto comparativo amplio, es importante subrayar que pese a que los sitios web de las dependencias ambientales de los gobiernos de la frontera norte cumplen en buena medida con los rubros "ofrecer servicios visibles y estructurados" y "transparencia de la información”, dichos sitios, especialmente a escala estatal y municipal, no están en condiciones para cumplir la mayoría de los objetivos planteados, especialmente los relacionados con "participación ciudadana", "importancia del sitio web" y "servicios accesibles a los ciudadanos". En este sentido, aunque hubo algunas consistencias entre los niveles de cumplimiento de algunos objetivos, el contexto de las dependencias ambientales no parece apuntalar hacia un solo e-Gobierno en la frontera norte sino hacia varios, dependiendo de la lógica de cada nivel de gobierno, puesto que en la mayoría de los sitios web estatales y municipales hubo variación significativa respecto de los objetivos cumplidos y no cumplidos.

\section{Conclusiones}

Independientemente de la importancia que adquiere la instrumentación de la web en la administración pública, en la evaluación de los resultados de su involucramiento queda todavía un aspecto exploratorio y en curso de implementación. En el marco de la incursión en estos contextos de investigación, nos percatamos de los escasos trabajos dedicados a la evaluación de sitios web gubernamentales relacionados con temáticas ambientales. Esto es válido a pesar de que existen interesantes iniciativas de evaluación, como las realizadas por Beierle y Cahill (2000) y la UNDESA 
(2012). Dichas investigaciones se enfocaron de manera prioritaria a evaluar sólo una parte de los objetivos que dieron sustento a la creación de estos sitios, como en el caso de Beierle y Cahill (2000) que evaluaron únicamente el rubro de la participación ciudadana y la UnDESA (2012) que inició apenas en 2012 la valoración de los servicios e información ambiental de los sitios web de las dependencias ambientales de 193 países. De esta manera, entre otros rubros propuestos por diferentes estudiosos de los sitios web de gobierno, quedan todavía sin evaluarse rubros de gran importancia, como la transparencia de la información, la accesibilidad a los servicios ofertados y la concurrencia y colaboración entre dependencias de gobierno. Esta misma necesidad, que parece estructurar un reclamo ciudadano, se convierte en un compromiso para participar en la elaboración y el mejoramiento de las metodologías existentes a fin de contar con una evaluación amplia y pertinente.

La aplicación de la metodología de evaluación elaborada en el marco del presente estudio logró poner de relieve el hecho de que no obstante que los sitios web revisados se encuentren haciendo esfuerzos diferenciados para ofertar servicios e información a los ciudadanos, estas iniciativas siguen siendo poco eficientes. De hecho, aun cuando se identificaron sitios web en línea, lo que constituye generalmente por sí solo una hazaña para los gobiernos locales, se encontraron indicadores que refutan la adecuada colocación en línea de servicios e información. En lo referente al cumplimiento de objetivos, se concluye que los sitios web de las dependencias ambientales evaluadas se preocupan más por presentar información y servicios de manera visible y estructurada. Lo que lleva a reflexionar en ello, debido a que es poco práctico ofrecer servicios visibles y estructurados si el acceso se lleva a cabo de manera inadecuada para el usuario. De la misma manera, los sitios web de los tres niveles de gobierno, al no cumplir con las pautas de "participación ciudadana”, dejan entrever que su lógica en línea está centrada en la comunicación y no en la interacción ciudadana y sus implicaciones, como los niveles de consulta y utilidad de los sitios creados.

En el marco de la presente investigación, los resultados evidenciaron que existe una brecha importante en el cumplimiento de los objetivos por parte de los sitios web de las dependencias ambientales de gobierno de los estados de la frontera norte. Estos sitios no cumplen en buena 
medida los objetivos presentes en los planes y programas de gobierno que motivaron su implantación y creación. Por ello, si realmente se pretende que los sitios web de las dependencias ambientales de gobierno sean instrumentos para mejorar la gestión ambiental, tal y como plantea la Semarnat $(2006,2011)$ y los planes y programas de gobierno, es necesario mejorar tanto la forma como el fondo de estos sitios para procurar incidir en la eficiencia de los procesos de gestión ambiental.

De manera general, la oferta de la dependencia ambiental federal fue la que cumplió en mayor medida los objetivos planteados en los planes y programas, seguido de los sitios web estatales; al último se ubicaron los sitios web de la autoridad municipal fronteriza. Esta última se caracterizó por un cumplimiento mínimo con los objetivos que motivaron la instrumentación de los sitios web evaluados, dejando entrever la importancia de contar con iniciativas concretas y una normatividad en la materia, por lo menos, a la imagen de las exhibidas a nivel de la administración pública federal (Gobierno de México, 2007). En este sentido, todo parece indicar que la correa de transmisión de las habilidades organizacionales, técnicas y normativas en el ámbito de la oferta ambiental online se encuentra ampliamente inoperante entre los diferentes niveles de gobiernos. Lo anterior se traduce en sitios web aislados, con contenidos ineficientes orientados hacia la comunicación política y sus corolarios: la propaganda y promoción. Por ello, en el caso de irrumpir una auténtica aspiración que atribuiría a los sitios web de las dependencias ambientales de gobierno un papel en la mejora de la gestión ambiental, tal y como lo establecen en la actualidad sus planes y programas de gobierno, sería quizá necesario proceder, antes que nada, por reposicionar los sitios existentes alrededor del ciudadano y sus necesidades.

Para finalizar, es importante subrayar que este trabajo constituye un primer acercamiento para evaluar los sitios web de las dependencias ambientales, y, por lo tanto, los aspectos conceptuales y metodológicos que le dieron sustento son mejorables en todos los sentidos. Bajo esta perspectiva, considerando que aún falta mucho por averiguar sobre este tema, resulta necesario encaminar los esfuerzos a futuro hacia una evaluación integral que busque generar mecanismo de retroalimentación y de cooperación intergubernamental. 


\section{Bibliografía}

Aguilar V., L. F. (2008). Nueva Gestión Pública. En L. F. Aguilar. Gobernanza y gestión pública (2da. ed.). México: Fondo de Cultura Económica.

Aguilar V., L. F. y Bustelo, M. (2010). Gobernanza y evaluación: Una relación potencialmente fructífera. En Gestión y Análisis de Políticas Públicas, (4), 23-50.

Alberro, I. (2010). Impacto de la economía política en la administración pública: Liberalismo económico y democracia. En J. L. Méndez (Coord.), Los grandes problemas de México. Políticas públicas (pp. 85-104). México: El Colegio de México.

Alshawi, S., Ali, A. y Alalwany, H. (junio, 2007). E-government evaluation factors: Citizen's perspective. Actas de la Conferencia Europea y Mediterránea de Sistemas de Información. Universidad Politécnica de Valencia. España.

Araiza, P., Gutiérrez D., M., Araiza Z., A., Sapién A., A., Piñón H., L. (2009). Niveles de gobierno electrónico: Revisión de literatura [Síntesis].

Banco Mundial. (2011). E-government definition. Recuperado de <http://web. worldbank.org $>$.

Barahona, J. C., Zuleta, R. y Calderón, O. (2010). Evaluación de sitios web del gobierno y municipalidades de Costa Rica. Costa Rica: InCAE Business School.

Beierle, T. y Cahill, S. (2000). Electronic democracy and environmental governance: A survey of the states. Washington: Resources for the Future.

Benjamin, M. y Whitley, E. (junio, 2004). Assessing UK e-Government websites: Classification and benchmarking. Trabajo presentado en la $12^{\text {th }}$ European Conference on Information Systems, Turku, Finlandia.

Bonina, C. (2005). Tecnologías de información y Nueva Gestión Pública: Experiencias de gobierno electrónico en México. México: Centro de Investigación y Docencia Económicas (CIDE), División de Administración Pública.

Bonina, C. y Cordella, A. (2008). The new public management, e-government and the notion of "public value": Lessons from Mexico. Proceedings of the AIs Special Interest Group on ICT and Global Development Workshop. París, Francia.

Bouzas, R. y Mahou, X. M. (2011). El análisis de las web institucionales: Una propuesta metodológica desde la perspectiva e-gob. II Congreso Internacional en Gobierno, Administración y Políticas Públicas. Madrid, España.

Briceño R., W. de J. y Ávila, N. (2010). Consideraciones microeconómicas sobre el papel del Estado en la economía de mercado. Negotium, Fundación Miguel Unamuno y Jugo, 6(17), 5-39.

Camilleri, J. A. y Falk, J. (1992). The end of sovereignty? The politics of a shrinking and fragmented world. Nueva York, Aldershot: Edward Elgar.

Cardozo B., M. I. (2006). La evaluación de políticas y programas sociales en México: El caso de los programas de desarrollo social en México. México: Miguel Ángel Porrúa. 
Castells, M. (2002). The internet galaxy. Reflections on the internet, business, and society. Oxford, Inglaterra: Oxford University Press.

Cerbino, M. y Richero, A. (Edits.). (2006). Gobernanza, políticas públicas y aplicaciones de internet. Quito, Ecuador: FLACSO.

Choudrie, J., Ghinea, G, y Weerakkody, V. (2004). Evaluating global e-government sites: A view using web diagnostic tools. Conferencias Académicas Ltd., Department of Information Systems and Computing, Brunel University, Uxbridge, Inglaterra.

Concha, S. (2006). Políticas públicas e internet. En M. Cerbino y A. Richero (Eds.), Gobernanza, políticas públicas y aplicaciones de internet (pp. 85-93). Quito, Ecuador: FLACSO.

Criado G., I. y Ramilo A,. M. C. (2001). Evaluación de la e-administración: Indicadores del rendimiento de las páginas web de las administraciones públicas. V Congreso Español de Ciencia Política y de la Administración La Laguna-Tenerife, España.

Cruz, S. P. (2003). Composición del presupuesto asignado a TIC en el gobierno federal. Política Digital. Recuperado de <www.politicadigital.com.mx $>$.

Escher, T., Margetts, H., Petrecek, V. y Cox, I. (2006). Governing from the Centre? Comparing the Nodality of Digital Governments. American Political Science Association. Oxford: Internet Institute.

Farge C., C. (2007). El Estado de bienestar. Enfoques, XIX, (1-2), 45-54.

Fragoso V., E. (2002). Gobierno electrónico: Evaluación de la percepción ciudadana (1). Boletín de Política Informática.

Gálvez G., B. (2010). ¿Cuánto gasta la administración pública federal en TIC? Política Digital, ejemplar de obsequio, 57, 44-46.

Gant, J. P., Gant, D. B. y Johnson, C. (2002). State web portals: Delivering and financing e-service. E-government series, The Pricewaterhouse Coopers Endowment for the Business of Government, Washington.

Gil-Corrales, M. Á. (2007). Crónica ambiental: Gestión pública de políticas ambientales en México. México: Fondo de Cultura Económica, Secretaría de Medio Ambiente y Recursos Naturales, Instituto Nacional de Ecología.

Gil-García, J. R., Mariscal, J. y Ramírez H., F. (2008). Gobierno electrónico en México. México: cIDE.

Gil-García, J. R., Arellano-Gault, D. y Luna-Reyes, L. F. (2010). Gobierno electrónico en México (2000-2006): Una visión desde la Nueva Gestión Pública. Ponencia presentada en el 11th. Annual International Conference on Digital Government Research, Puebla, México.

Gobierno de Australia. (2010). Webguide. Recuperado de < webguide.gov>.

Gobierno de Canadá. (2007). Standards and Guidelines. Recuperado de <www.tbssct.gc.ca $>$.

Gobierno de Chile. (2003). Guía para desarrollo de sitios web 1.0. Chile: Ministerio Secretaría General de Gobierno. 
Gobierno de Chile. (2006). Guía Web 2.0. Chile: Ministerio Secretaría General de Gobierno.

Gobierno de Costa Rica. (2007). Guía para el desarrollo de sitios web del gobierno de Costa Rica. Costa Rica: Secretaria Técnica de Gobierno Digital.

Gobierno de España. (2004). Norma UNE 139803:2004 sobre aplicaciones informáticas para personas con discapacidad: Requisitos de accesibilidad para contenidos web. España: Asociación Española de Normalización y Certificación.

Gobierno de España. (2007). Ley 11/2007, de 22 de junio, de acceso electrónico de los ciudadanos a los servicios públicos. España.

Gobierno de España. (2009). Real decreto 1671/2009, de 6 de noviembre de acceso electrónico de los ciudadanos a los servicios públicos. España.

Gobierno de Francia. (1999). Circulaire du 7 octobre 1999 relative aux sites internet des services et des établissements publics de l'Etat del 12 de octubre de 1999, 1999 (NI: PRMx9903708C, № 237). Recuperado de <www.legifrance.gouv.fr>.

Gobierno de India. (2009). Guidelines for Indian government websites. India: Department of Information Technology, Ministry of Communications and Information Technology.

Gobierno de Inglaterra. (2002a). Guidelines number TG109: Minimum technical standards.

Gobierno de Inglaterra. (2002b). Guidelines number TG110: Making PDF files usable and accessible.

Gobierno de Inglaterra. (2009a). Guidelines number TG102: Delivering inclusive websites.

Gobierno de Inglaterra. (2009b). Guidelines number TG117: Browser testing.

Gobierno de Inglaterra. (2009c). Guidelines number TG122: Exposing your website to search engines.

Gobierno de Inglaterra. (2010a). Guidelines number TG101: Naming and registering websites and social media channel.

Gobierno de Inglaterra. (2010b). Guidelines number TG116: Measuring website usage.

Gobierno de Inglaterra. (2010c). Guidelines number TG123: Search engine optimisation.

Gobierno de Inglaterra. (2010d). Guidelines number TG130: Service availability.

Gobierno de Inglaterra. (2011). Guidelines number TG136: Moderating online discussions.

Gobierno de México. (2007). Guía para el desarrollo de sitios web de la administración pública federal. México: Presidencia de la República.

Gobierno de Uruguay. (2009). Guía para diseño e implementación de portales estatales. Uruguay: Agencia para el Desarrollo del Gobierno de Gestión Electrónica y la Sociedad de la Información y el Conocimiento.

González M., J. C. (2005). La administración pública como ciencia: Una aproximación a su objeto de estudio. Espacios públicos, 8(015), 162-175. 
Jesús Ignacio Castro Salazar y Djamel Toudert/Hacia una metodología de evaluación de los sitios web

Graham, S. (1998). The end of geography or the explosion of space? Conceptualizing space, place and information technology. Progress in Human Geography, 22(2), 165-185.

Gupta, M. P. y Debashish, J. (2003). E-government evaluation: A framework and case study. Pergamon, 20, 365-387.

Held, D. y McGrew, A. (2003). Globalización/antiglobalización. Sobre la reconstrucción del orden mundial (Caps. 1,2, 4 y 9). Barcelona, España: Paidós Ibérica.

Kraft, M. y Furlong, S. (2004). Public policy: Politics, analysis and alternatives. Washington: CQC Press.Kunstelj, M. y Vintar, M. (2004). Evaluating the progress of e-government development: A critical analysis (pp. 131-148). Ljubljana, Slovenia: Information Polity, University of Ljubljana, Faculty of Administration.

Lara N., P., Martínez U., J. Á. y Gómez Fernández-Cabrera, J. (2004). Administración electrónica: Gestión de la información + conocimiento. Barcelona: Planeta- UOC, S.L.

Leff, E. (2002). Saber ambiental. Sustentabilidad, racionalidad, complejidad, poder, PNUMASiglo XXI (3ra ed.). México: Centro de Investigaciones Interdisciplinarios en Ciencias y Humanidades.

Luna-Reyes, L. J., Gil-García, R. y Rojas-Bandera, J. S. (2007). An exploratory study of electronic government and state portals in Mexico. En M. GascóHernández (Ed.). Latin America online: Cases, successes and pitfalls. (pp. 116 156). Hershey, Pensilvania, Estados Unidos: Idea Group Inc.

Luna-Reyes, L.F., Hernández G., J. M. y Gil-García, J. R. (2009). Hacia un modelo de los determinantes de éxito de los portales de gobierno estatal en México. Gestión y Política Pública, XVIII(2), 307-340.

Luna-Reyes, L. F., Gil-García, J. R. y Sandoval, R. (2010). Reflexiones sobre la evaluación de los portales de gobierno en internet. Espacios Públicos, 13(27), 67-78.

Marcos, M. C. y Rovira, C. (2005). Evaluación de la usabilidad en sistemas de información web municipales: Metodología de análisis y desarrollo. [Congreso] Barcelona, España: Isko, Universitat Pompeu Fabra.

Martinelli, A. (2003). Governments, communities and global governance. International Sociology, 18(2), 291-323.

Martínez F., J. (2003). Ver para creer la información pública ciudadana en América Central: Un estudio desde la sociedad civil. San José, Costa Rica: Fundación Acceso.

Martínez V., J. (2007). Nueva gerencia pública: Un análisis comparativo de la administración estatal en México. México: Miguel Ángel Porrúa.

McLaughlin, K., Osborne, S. y Ferlie, E. (2002). New public management. Current trends and future. Prospect. Londres, Inglaterra: Routledge.

Mosse, B. y Whitley, E. (junio, 2004). Assessing UKe-Government website: Classification and benchmarking. Trabajo presentado en la $12^{\text {th }}$ European Conference on Information Systems, Turku, Finland. 
Obi, T. (2012). The 2012 Waseda University International e-Government Ranking released. Tokyo, Japón: Universidad de Waseda.

Olías de Lima, B. (2001). La Nueva Gestión Pública. Madrid, España: Prentice Hall.

OCDE (Organización para la Cooperación y el Desarrollo Económicos). (2003a). The e-Government imperative: Main findings. OECD Observer.

ocDE (Organización para la Cooperación y el Desarrollo Económicos). (2003b). The e-Government imperative. París, Francia: ocDE.

Parsons, W. (2007). Introducción a la teoría y práctica del análisis de políticas públicas. México: FLACSO.

Programa de las Naciones Unidas para el Desarrollo. (2011). Areas of governance. Governance Assessment Portal. Recuperado de < http://www.gaportal.org >.

Relyea, H. C. (2002). E-gov: Introduction and overview. Government Information Quarterly, 9-35.

Rodríguez, G. S. (2004). Modernización y transparencia de la gestión pública. Revista de Derecho, (21), 1-23.

Rodríguez, M. C. (2006). Investigación sobre el estado de avance del gobierno electrónico en Colombia a nivel municipal, regional y nacional. Bogotá, Colombia: Universidad de los Andes.

Ruiz A., L. (2006). La nueva gerencia pública: Flamante mito de un viejo paradigma. Espacios Públicos, 9(017), 239-251.

Sánchez G., J. J. (2009). La administración pública de Vicente Fox: Del Modelo Estratégico de Innovación Gubernamental a la Agenda de Buen Gobierno. Espacios Públicos, 12(24), 8-31.

Sánchez G., J. J. (2010). ¿Innovando en la gestión pública? La experiencia mexicana en los gobiernos locales. Espacios Públicos, 13(27), 10-32.

Sandoval C., S. A. (2008). Gobierno electrónico: Elementos de facilidad de uso y valor público de los portales de internet local en México (Tesis). Flacso, México.

Sandoval-Almazán, R. J., Gil-García, R. y Luna-Reyes, L. F. (2011). Manual para evaluación de portales estatales en México. México: Centro de Investigación y Docencia Económicas, Universidad Autónoma del Estado de México, Universidad de las Américas Puebla.

Semarnat (Secretaría de Medio Ambiente y Recursos Naturales). (2006). La gestión ambiental en México. México: Autor.

Semarnat (Secretaría de Medio Ambiente y Recursos Naturales). (2007). Programa Sectorial de Medio Ambiente y Recursos Naturales (PSMARN) 2007-2012. México: Autor.

Semarnat (Secretaría de Medio Ambiente y Recursos Naturales). (2011), Quinto informe de labores. México: Autor.

SPABC (Secretaría de Protección al Ambiente de Baja California). (2009). Programa Estatal de Protección al Ambiente de Baja California 2009-2013. Periódico Oficial. 
Sotelo N., A. (2006). Las TIC, un medio para alcanzar un buen gobierno. Política Digital. Recuperado de <www.politicadigital.com.mx $>$.

Toudert, D. (2003). La integración telemática en México: Algunos límites y contradicciones de la planeación centralizada. Región y Sociedad, xv(28), 193-223.

Toudert, D. (2007). Algunos rasgos y particularidades de la polarización territorial de la producción de contenidos web en México. Revista Sociedad y Territorio del Colegio Mexiquense, vI(23), 579-611.

UNDESA (United Nations Department of Economic and Social Affairs). (2010). E-government survey 2010. Nueva York: un Publishing Section.

Undesa (United Nations Department of Economic and Social Affairs). (2012). E-government survey 2012. Nueva York: un Publishing Section.

West, D. (2008). Improving technology utilization in electronic government around the world, 2008. Estados Unidos: Universidad de Brown, Governance Studies at Brookings.

Whittingham, M. V. y Ospina, S. (2000). Reflexiones sobre una propuesta de evaluación de resultados de la gestión pública: El Sistema Nacional de Evaluación de Resultados (Sinergia) en Colombia. CLAD Reforma y Democracia, (21).

Wolton, D. (2000). Internet et après? Une théorie critique des nouveaux media. París, Francia: Flamarion. 